\title{
Comparison of Electrical Responses of Terminals, Axons, and Somata of a Peptidergic Neurosecretory System
}

\author{
Misako Nagano a and I. M. Cooke \\ Békésy Laboratory of Neurobiology, University of Hawaii, Honolulu, Hawaii 96822
}

Spontaneous and evoked electrical activity was recorded intracellularly from somata, axons, and terminal dilatations of an isolated peptidergic neurosecretory system, the $X$-organ-sinus gland, of the crabs Cardisoma carnifex and Podophthalmus vigil in order to compare their electrical characteristics. Spontaneous impulse activity was present in most penetrations and included irregular and pacemakerlike firing, as well as patterned activity (bursting). Extracellular recording showed that spontaneous impulses and bursting originate in a proximal region of the axon tract. Somata vary from being electrically nonresponsive to having overshooting impulses with a relatively slow rate of rise. Overshooting impulses were consistently recorded from axons and terminals. Regional differences include (1) a longer action potential duration in terminals, (2) ability of axons and terminals but not somata to sustain repetitive firing, (3) presence of depolarizing afterpotentials in axons but of hyperpolarizing afterpotentials in somata and terminals, and (4) occurrence of impulse broadening during repetitive firing in some terminals but not in axons or somata. Somata and terminals sustained reduced and slowed, but regenerative impulses in nominally Na-free saline and showed alterations of waveform in nominally Ca-free salines, while axons showed no regenerative responses in $\mathrm{Na}$-free saline and no change of impulse form in Ca-tree saline. Terminal responses in the presence of tetraethylammonium chloride (TEA) (50 mM) or Ba (50 mm) exhibited long depolarized plateaus, while impulses of somata were much less prolonged. Bursts often took the form of impulses superimposed on a depolarized plateau. Bursts could be evoked by single stimuli applied to the axon tract but not by current passed intracellularly. After addition of TTX, axon tract stimulation evoked plateaus without superimposed impulses. Terminals exhibit specialization of their electrical responses by comparison to axons and somata in having long-duration action potentials attributable to participation of $\mathrm{Ca}$, capability of sustained firing, impulse broadening, and channels

\footnotetext{
Received Dec. 23, 1985; revised July 16, 1986; accepted Sept. 15, 1986.

We thank Ms. Beverley Haylett for unfailing technical assistance, Dr. Martin Vitousek for aid in obtaining crabs, Dr. E. Stuenkel for criticism of the manuscript, and Ms. Carol Kosaki for its preparation. Supported by NSF Grants BNS8107289 and BNS84-04459, and NIH Grant NS 15453 to I.M.C., grants from the University of Hawaii Foundation, and a Traveling Fellowship from the Japan Ministry of Education (M.N.).

Correspondence should be addressed to Ian M. Cooke, Békésy Laboratory of Neurobiology, University of Hawaii, 1993 East-West Road, Honolulu, HI 96822.

Present address: National Institute for Physiological Sciences, Myodaiji, Okazaki 444, Japan.

Copyright (c) 1987 Society for Neuroscience $0270-6474 / 87 / 030634-15 \$ 02.00 / 0$
}

supporting sustained inward currents, all of which might enhance the admission of $\mathrm{Ca}$ for initiation of peptide secretion.

The importance of neuropeptides to neuronal and endocrine function is rapidly gaining recognition. Information on the electrophysiological characteristics of peptidergic nerve terminals that might be important to their secretory function is largely indirect because the small size of terminals precludes intracellular recording. An exception is the neurosecretory system of the crustacean eyestalk, the X-organ-sinus gland (XOSG) system. In certain species of crabs, the axon terminals include dilatations reaching sizes of up to $30 \mu \mathrm{m}$. Further, the terminals are organized in a compact neurohemal organ (the sinus gland, SG) that can be isolated, together with the axon tract and the somata of origin (the $\mathrm{X}$-organ, $\mathrm{XO}$ ), as an intact neurosecretory system with no non-neurosecretory tissue other than connective tissue and glia. This paper provides a comparison of the elcctrophysiological characteristics of neurosecretory terminals with those of the axons and somata as investigated by intracellular recording from each region. The terminals show a number of specialized characteristics appropriate to their secretory role. The observations augment previous reports of recordings from terminals (Cooke, 1985) and from terminals and somata (Stuenkel, 1985). Some of the observations have been briefly described in abstracts and review chapters (Cooke, 1981; Nagano and Cooke, 1981, 1983; Nagano, 1982; Cooke and Stuenkel, 1985).

In crabs, a cluster of about 150 large (ca. $60 \mu \mathrm{m}$ diameter) neurons, the $\mathrm{XO}$, sends axons via the sinus gland nerve to the sinus gland. These contribute at least $90 \%$ of the terminals comprising this neurohemal organ. They exhibit heterogeneity in their EM fine structure (Weatherby, 1981) and histochemistry (Potter, 1956; Rehm, 1959), as do the terminals. The importance of the heterogeneity is uncertain in view of evidence that $90 \%$ of the total peptide content of XOSG systems derives from a single biosynthetic precursor (Stuenkel, 1986). Morphological studies and biochemical studies (for reviews, see Cooke and Sullivan, 1982; Keller, 1983; Newcomb, 1983; Stuenkel, 1983) indicate purely peptidergic secretion by this system.

The secretory responsiveness of the in vitro system has been described (Cooke et al., 1977; Cooke and Haylett, 1984; Stuenkel, 1985) and shows the system to conform closely to secretory mechanisms of vertebrate and other neurosecretory systems (for a review, see Rubin, 1982). Direct correlation of secretory with electrical responses recorded intracellularly from terminals and somata is reported by Stuenkel (1985). Thus, electrophysiological characterization of peptidergic neurons, particularly their secretory terminals, uniquely possible in this crab system, may provide information of importance to understanding peptidergic 
secretion in other systems. Our results on certain crab species are generally similar to previous observations on XO somata of crayfish (Iwasaki and Satow, 1969, 1970, 1971; Glantz et al., 1983) and thus indicate generalizability among Crustacea.

\section{Materials and Methods}

Electrophysiological recordings were obtained from isolated XOSG neurosecretory systems of the eyestalks of 2 species of crabs, Cardisoma carnifex and Podophthalmus vigil. Cardisoma, a semiterrestrial crab, were air-shipped from Fanning Island or Christmas Island, and held for periods of days to months in outdoor cages. They were provided with freshwater and seawater and were fed rat pellets (Purina). Podophthalmus, the long-eyed Hawaiian swimming crab, were trapped in Kaneohe Bay, Oahu, and held in outdoor aquaria provided with recirculated seawater. Dissections, performed under a binocular microscope, isolated the neurohemal structure (SG) and distal portion of the axon tract completely; some tissue was left surrounding the $\mathrm{XO}$ (somata) and the proximal portion of the SG tract, in order to preserve most of the axon collaterals. The length of the isolated preparation was $2-3 \mathrm{~mm}$ for Cardisoma and 3-5 mm in Podophthalmus, which has a longer axon tract. The preparations were pinned with cactus spines in a Sylgard (Dow-Corning) lined double chamber that was coated with a thin layer of agar to assist smooth perfusate flow. The SG tract lay in a groove through the $0.5-\mathrm{mm}$-wide ridge separating the chambers. In the majority of experiments the groove was sealed with petroleum jelly (Vaseline). Each chamber held a volume of ca. $0.3 \mathrm{ml}$. The compartments were continuously and independently perfused with a peristaltic pump at rates of $0.1-0.3 \mathrm{ml} / \mathrm{min}$. The normal saline contained the following (in mM): $\mathrm{NaCl}, 440 ; \mathrm{KCl}, 11.3 ; \mathrm{CaCl}_{2}, 13.3 ; \mathrm{MgCl}_{2}, 26.3 ; \mathrm{Na}_{2} \mathrm{SO}_{4}, 23.3$; HEPES 4, pH 7.5. Sodium-free saline was obtained by replacing both $\mathrm{NaCl}$ and $\mathrm{Na}_{2} \mathrm{SO}_{4}$ with choline chloride. Nominally Ca-free saline was made by omitting the $\mathrm{CaCl}_{2}$ and substituting $\mathrm{MgCl}_{2}$ or an osmotically equivalent amount of $\mathrm{NaCl}$. In $\mathrm{Ba}$-containing saline, $\mathrm{Na}_{2} \mathrm{SO}_{4}$ was omitted and replaced with $\mathrm{NaCl}$. In tetraethylammonium chloride (TEA)containing saline (usually $50 \mathrm{~mm}$ ) $\mathrm{NaCl}$ was reduced by an equivalent amount. Other pharmacological agents were added to the normal saline. Experiments were performed at room temperature $\left(22-25^{\circ} \mathrm{C}\right)$.

Intracellular recordings were made with nonfilament-bearing glass microelectrodes, filled with $3 \mathrm{M} \mathrm{KCl}$, beveled to resistances of ca. 60 M $\Omega$. Amplifiers provided with constant-current "bridge" circuits (WPI 701) permitted recording and current-passing through the same electrode. An agar-saline- $\mathrm{KCl}-\mathrm{Ag}-\mathrm{AgCl}$ reference electrode was used and monitored current by means of a virtual ground current-to-voltage converter. Pt-wire electrodes placed in each chamber could be switched between a high-impedance AC preamplifier (Grass P15) or stimulus isolation unit (Grass SIU5) to monitor impulses of the axon tract or stimulate it across the Vaseline seal. Stimulation could also be accomplished in the absence of the Vaseline.

\section{Results}

Spontaneous activity and its origin

All of the isolated XOSG preparations exhibited "spontaneous" electrical activity in extracellular recording from the SG tract, as well as in most intracellular recordings from terminals, axons, and somata. We briefly describe this spontaneous activity, as the presence of apparently endogenous patterning or bursting in many intracellular recordings and of a distinct site for initiation of spontaneity, including bursting, constitute evidence for regional specialization of these neuroendocrine cells.

Typically, an hour or more after completion of the dissection, we observed a relatively constant level of multiunit impulse firing, usually without obvious patterning, which persisted with little change for extended periods (up to $24 \mathrm{hr}$ in one case). Examination of the polarity of the recorded deflections showed that most impulses propagated from the region of the somataproximal neurites and collaterals toward the terminals. During simultaneous extracellular recording and intracellular recording from terminals, in 63 out of 99 cases we could identify a unit of constant amplitude and form in the extracellular record that invariably immediately preceded an action potential recorded in the terminal (see Fig. 1, $a, d$ ). In only 4 cases did such simultaneous recording indicate initiation of action potentials on the terminal side of the barrier (Fig. 4, $B, C$ ).

In preparations in which a time-locked preceding extracellular deflection could be associated with the terminal action potential, the rate of both could be altered by passing current at the terminal (decreased by passage of hyperpolarizing current, increased by depolarizing current), and initiation of the impulses continued to take place proximal to the Vaseline barrier. Several terminals in which there was no spontaneous activity, when stimulated with intracellular depolarizing current, showed an impulse preceding the terminal impulse in the extracellular record, indicating initiation of the impulse proximally. The observations indicate that a site of minimum threshold for impulse initiation exists in the proximal axon. This site is apparently accessible to influence electrotonically from the terminal. Other observations consistent with this conclusion are given in Cooke (1985) and Stuenkel (1985).

Intracellular recordings were obtained from 99 terminals, 14 axons, and 25 somata. Spontaneous activity was present in 77 of the terminals (77\%), 7 of the axons (50\%), and $16(64 \%)$ of the somata recordings. The activity most frequently took the form of regular action potential firing at a slow rate, usually less than $1 / \sec$ (Fig. 1A). Bursting, in a diversity of patterns, was observed from each of the sites. Recordings from different penetrations in the same preparation varied in that some showed no spontaneous activity; others, regular firing; and some, patterned activity. Changes in activity, from none to slow regular firing, and from bursting to regular firing, were recorded while holding a single penetration.

\section{Bursting}

Because of its close correlation with peptidergic secretory activity in a number of systems, we report in some detail the observation of bursting in recordings from the XOSG system. Approximately one-third (26) of the terminals that showed spontaneous firing showed grouping or patterning of their spontaneous impulse activity ("bursting").

While in the great majority of preparations the extracellular activity consisted of a more or less regular barrage of firing, in a few preparations of both species studied here, the extracellular activity appeared to wax and wane in a coordinated fashion, the active and quiescent episodes each lasting tens of seconds (Fig. 8). Many of the intracellular recordings from such preparations exhibited bursting. The impulse bursts recorded intracellularly were coordinated with periods of increased extracellular activity in these preparations.

A wide variety of bursting patterns was recorded (Figs. 1, $B-$ $D$ ) but none sufficiently often to permit generalizations. Common characteristics of terminals that tended to burst included a relatively high resting potential (more negative than $-60 \mathrm{mV}$ ), often showing random, small voltage fluctuations or appearing "noisy"; and input resistance increases during imposed hyperpolarization (see Cooke, 1985). Impulses of a burst were often superimposed on a sustained, underlying depolarization, and ceased with spontaneous hyperpolarization of the membrane potential (Fig. 1C).

Figure $1 B$ presents records from a terminal that displayed rhythmic activity having the longest period observed: A train of impulses at about $0.3 / \mathrm{sec}$ superimposed on a sustained de- 
TERMINAL

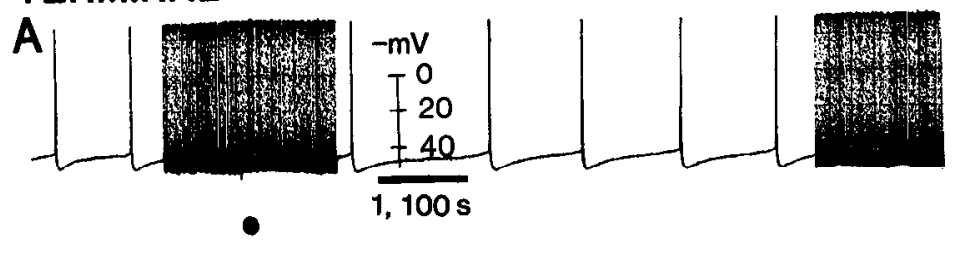

a

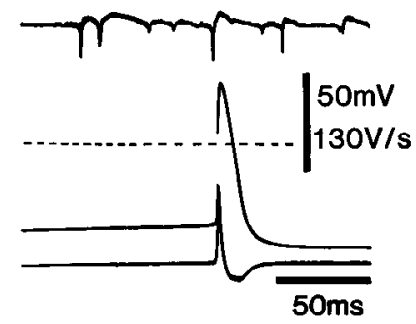

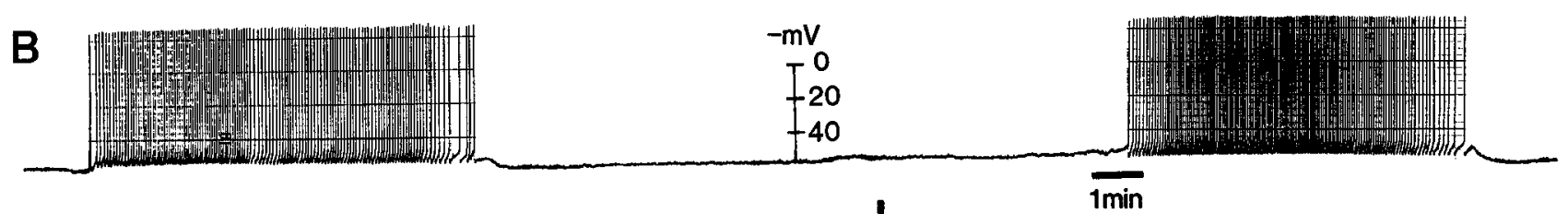

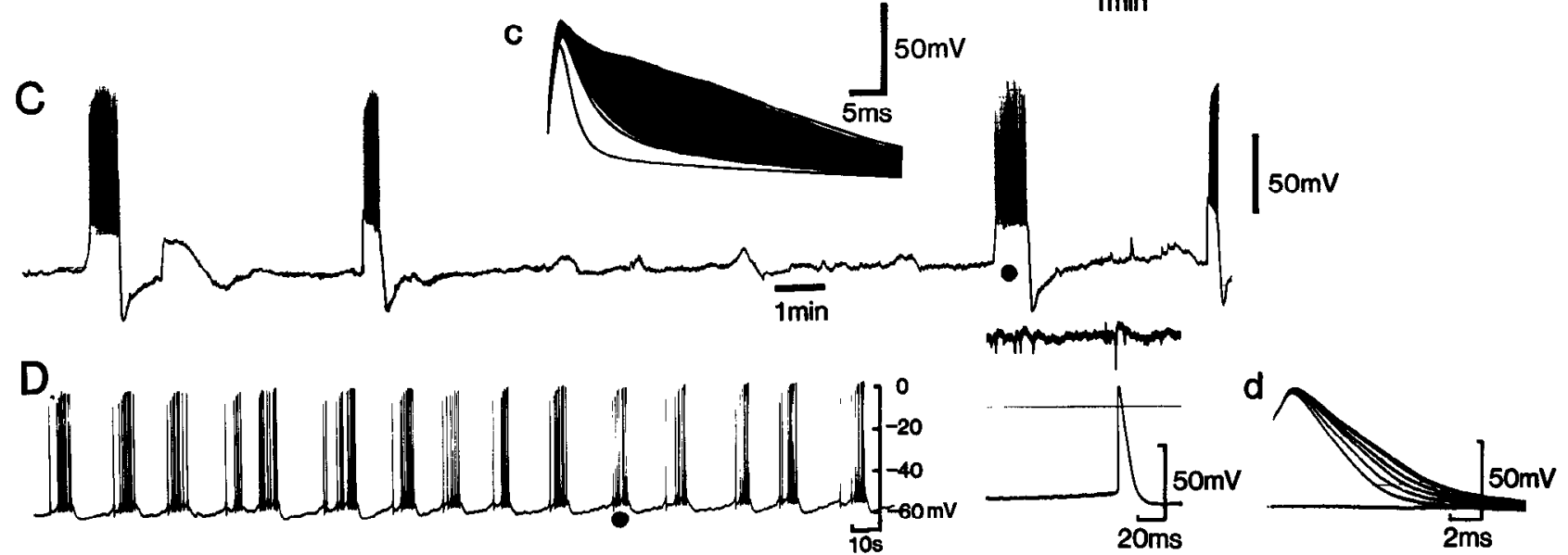

Figure 1. Spontaneous electrical activity recorded intracellularly from peptidergic neurosecretory terminals. $A$, Pacemakerlike firing of overshooting action potentials at ca. $1 / \mathrm{sec}$ (penwriter record at 2 speeds; bar, $1 \mathrm{sec}$ or $100 \mathrm{sec}$ ). Oscilloscope frame (a) recorded at the dot on the penwriter record includes extracellular recording from the axon tract (upper trace) and passive differentiation of the intracellular recording (lowest trace). The extracellular impulse immediately preceding the intracellular one was always present. Its polarity indicates proximal to distal propagation. Broken line indicates $0 \mathrm{mV} . B$, Patterned spontaneous firing. Bursts lasting over 6 min recurred regularly at intervals of ca. 20 min; maximum intraburst frequency was ca. $0.3 / \mathrm{sec}$; no impulse broadening was observable. Note that the depolarization underlying impulse firing was sometimes sustained after cessation of firing. (See also Fig. 14A). $C$, Irregularly bursting activity. The irregular, noisy baseline is consistently associated with bursting. Note that impulses are superimposed on a depolarized plateau, the occurrence of a depolarized plateau without superimposed impulse firing, sharp hyperpolarization following bursts. Intraburst firing rates reached $12 / \mathrm{sec}$. The intracellular recording was maintained for $8 \mathrm{hr}$, and activity similar to that shown was observed throughout this period. Frame inset $(c)$ displays the impulses of the burst marked on the penwriter record superimposed to show impulse broadening (ca. 6-fold at half-amplitude). $D$, Regularly bursting activity. Bursts lasting 5-10 sec, consisting of 6-10 impulses are superimposed on an underlying slow depolarization (penwriter record displays ca. $6 \mathrm{~min}$ ). Middle frame: First impulse of a burst displayed with extracellular recording showing associated impulse; polarity indicates proximal to distal propagation. $d$, Impulses of the marked burst superimposed to show broadening (ca. 30\% at half-amplitude). Note unchanged peak, notch on the rising phase, interpreted as axon-to-terminal invasion delay. $A-D$ are from different preparations, all Cardisoma carnifex.

polarization of about $10 \mathrm{mV}$ from resting potential lasted approximately $6 \mathrm{~min}$ and was repeated every $20 \mathrm{~min}$. The individual impulses did not show progressive increase of duration ("spike broadening") as was often seen in other bursting terminals (see below). The underlying depolarized plateau is most clearly seen at the end of a firing period, when it is sustained some seconds after the cessation of impulse firing.

A type of bursting observed from several terminals is illustrated in Figure $1 C$. In these terminals, the resting potential was high (usually about $-70 \mathrm{mV}$ ), noisy, and showed, in addition, large, slow fluctuations. These periodically led to a 10-40 sec period of impulse firing from a more depolarized plateau (typically at $-50 \mathrm{mV}$ ), during which rates as high as $12 / \mathrm{sec}$ were observed. The firing was terminated by repolarization from the sustained plateau and a period of sharply hyperpolarized membrane potential. The phenomenon of spike broadening is illustrated in this example: The impulses during bursts showed marked slowing of their repolarizing phase (Fig. 1c). This ter- minal was held, and the pattern illustrated was seen to persist over a period of $8 \mathrm{hr}$.

The patterned firing illustrated in Figure $1 D$ is illustrative of the type of bursting behavior recorded most frequently from the terminals. In this example, bursts lasting 5-10 sec recurred at rates of 2-3/min and consisted of 6-10 impulses superimposed on a sustained depolarization of ca. $10 \mathrm{mV}$. Intraburst firing frequency reached rates of $6 / \mathrm{sec}$. Successive impulses during individual bursts showed progressive broadening (Fig. 1d). The main variation in this general pattern involved the duration of bursts (up to $1 \mathrm{~min}$ ), and thus the number of impulses per burst and the frequency of bursts, frequency being inversely related to burst duration. A few examples of bursting having this general pattern were recorded from somata. The suggestion that spike broadening is significant for facilitation of secretion from terminals gains support from the failure to observe impulse broadening in any of these soma recordings (see below).

Several of the preparations exhibiting spontaneous bursting 


\begin{tabular}{|c|c|c|c|c|c|c|}
\hline & $\begin{array}{l}\text { Resting } \\
\text { potential } \\
(\mathrm{mV})\end{array}$ & $\begin{array}{l}\text { Overshoot } \\
(\mathrm{mV})\end{array}$ & $\begin{array}{l}\text { Rate of rise } \\
(\mathrm{V} / \mathrm{sec})\end{array}$ & $\begin{array}{l}\text { Rate of fall } \\
\text { (V/sec) }\end{array}$ & $\begin{array}{l}\text { Duration } \\
\text { (msec) }\end{array}$ & $\begin{array}{l}\text { After- } \\
\text { potential } \\
(n)\end{array}$ \\
\hline \multicolumn{7}{|l|}{ Terminals } \\
\hline Spontaneous & $\begin{array}{l}60 \pm 1.9 \\
(76)\end{array}$ & $20.5 \pm 1$ & $81.7 \pm 5.0$ & $28.6 \pm 2.9$ & $9.5 \pm 0.5$ & $45(\mathrm{H})$ \\
\hline Quiescent & $\begin{array}{l}77.8 \pm 4.1 \\
(17)\end{array}$ & $(68)$ & (15) & (15) & $(59)$ & \\
\hline \multicolumn{7}{|l|}{ Axons } \\
\hline Spontaneous & $\begin{array}{c}63.9 \pm 5.3 \\
(7)\end{array}$ & $15.3 \pm 3.3$ & $107.3 \pm 11.5$ & $35.0 \pm 8.4$ & $5.9 \pm 0.6$ & \\
\hline Quiescent & $\begin{array}{l}87.1 \pm 6.2 \\
(7)\end{array}$ & (7) & (3) & (2) & (6) & 7 (D) \\
\hline \multicolumn{7}{|l|}{ Somata } \\
\hline Spontaneous & $\begin{array}{l}49.7 \pm 3.2 \\
(15)\end{array}$ & $13.0 \pm 2.4^{a}$ & $36.1 \pm 5.6$ & $30.5 \pm 7.9$ & $7.8 \pm 0.6$ & $5(\mathrm{H})$ \\
\hline Quiescent & $\begin{array}{l}67.0 \pm 7.5 \\
(7)\end{array}$ & (9) & (3) & (13) & (13) & \\
\hline
\end{tabular}

were tested, and all were found to respond with a burst of impulses to a single brief stimulus applied to the SG tract via the Vaseline bridge (Fig. 14, B, C). Stimuli were effective only if they followed a spontaneous burst by an interval at least as long as the duration of the burst. Bursts could not be evoked by current pulses passed through an electrode in a terminal or in a soma, however, supporting the suggestion that bursting is initiated and organized at a specialized site. A few nonspontaneously bursting, infrequently firing, or silent preparations responded to a brief stimulus of the axon tract with burst firing (Fig. 13). Evoked bursts resembled spontaneous bursts in their temporal patterning but were usually of shorter duration. The impulse firing was preceded by depolarization to a plateau from which impulses arose, and repolarization from the plateau followed cessation of impulse firing, as was also the case for spontaneous bursts. The possibility that the plateau potential represents a regional regenerative response of the neuron separable from impulse generation is suggested by these observations. The ability to evoke the plateau response without action potentials during perfusion with TTX-containing saline, as described further below, also supports this view.

\section{Differences in electrical parameters of terminals, axons, and somata form of action potentials}

A number of differences in the electrical activity recorded from terminals, axons, and somata are apparent. Those units that did not show spontaneous active responses were routinely tested by stimulating the axon tract extracellularly or by passing depolarizing current pulscs through the recording microelectrode. Those in which spontaneous potentials were compared with evoked responses showed no marked differences between these. Measurements of several electrical parameters are summarized in Table 1. Perhaps the most interesting observation is that terminal action potentials have distinctly longer durations (ca. $10 \mathrm{msec}$, measured at half-amplitude) than do those of axons (ca. $6 \mathrm{msec}$ ) or somata (ca. $8 \mathrm{msec}$ ). Units that exhibited spontaneity, as a group, had less polarized resting potentials than those that did not. While action potentials consistently exhibited sizable overshoots in recordings from terminals and axons (20 and $15 \mathrm{mV}$, respectively), only about half of the somata recorded exhibited overshooting action potentials. In some somata, presumably, the action potential arises in the proximal axon but does not invade the soma, being recorded there in electronically decremented form. Not included thus far in our discussion of soma recordings are some dozens of penetrations (the number was not tabulated) made in the area of the XO in which a stable resting potential was noted, but no active responses were observable, either spontaneous or to depolarizing current pulses or extracellular stimulation of the SG tract.

\section{Repetitive firing ability}

Further differences in the electrical activity of different regions of the neurosecretory cells were observed when impulses were initiated by repetitive axonal stimulation or by long depolarizing current pulses. In recordings from a somata that exhibited overshooting potentials, the degree of overshoot declined with each successive impulse if the axon was stimulated at rates exceeding 1/sec (Fig. 2). During sustained depolarizing current pulses, action potentials were ultimately reduced to small oscillations. By contrast, in terminals, undiminished action potentials were observable in response to axonal stimulation rates of up to $5 / \mathrm{sec}$, and in a few instances, higher rates. Axons sustained rates of at least $20 / \mathrm{sec}$. Both terminals and axons responded with a train of impulses of undiminished amplitude for an indefinite period during passage of depolarizing current pulses (Fig. 2). Some terminals took up a relatively stable firing rate immediately and maintained it for tens of seconds (see Fig. 9 in Cooke, 1985); others, as in Figure 2, showed some increase in successive intervals between impulses as the current-passing continued.

\section{Impulse broadening}

In addition to the longer duration of action potentials in terminals relative to other parts of the neuron, a high proportion of the terminals exhibits spike broadening during repetitive ac- 
Figure 2. Comparison of responses to depolarizing current of a terminal, axon, and soma. Top frames, Responses of the same terminal to 2 magnitudes of depolarizing current passed via a "bridge" circuit through the recording electrode (current monitor, upper trace; r.p. $-59 \mathrm{mV}$; Podophthalmus vigil). Bottom frames, Similar recording from axon $(0.9 \mathrm{nA}$, r.p. $58 \mathrm{mV}, P$. vigil $)$ and soma (current: $1 \mathrm{nA}$, r.p. $-52 \mathrm{mV}, C$. carnifex; calibration applies also to axon). Note that impulse amplitude declined during repetitive firing in the soma but not in the terminal or axon.
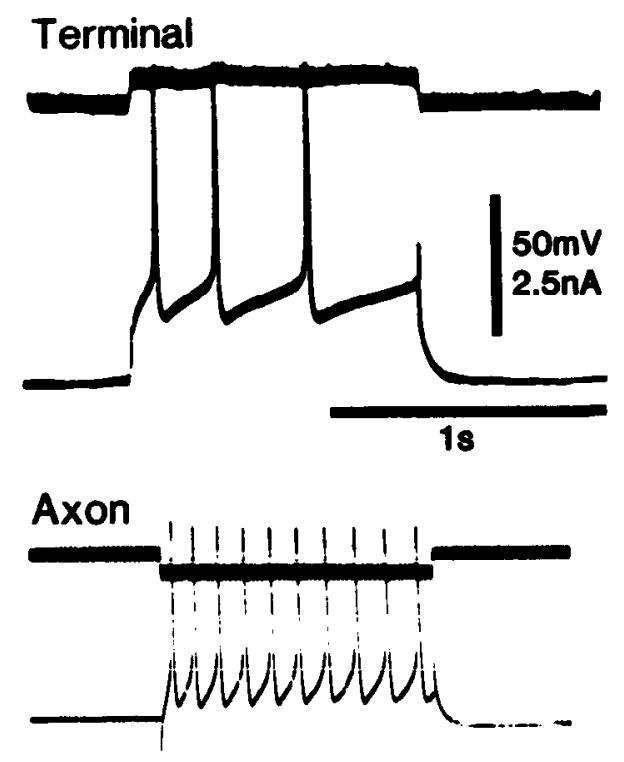
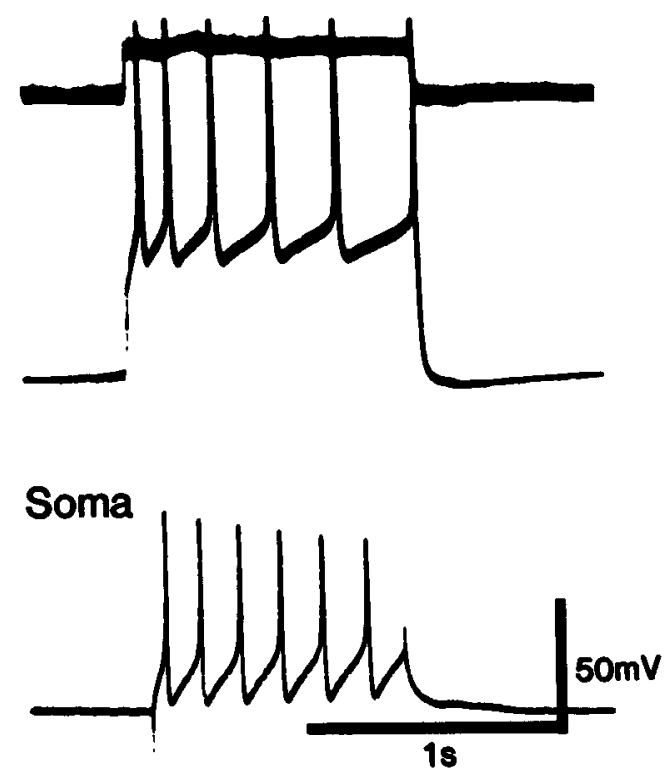

tivity (Cooke, 1977, 1981, 1985). The impulse broadening is the result of a slower rate of fall or, in some cases, the development of a shoulder during the falling phase. In a majority of the terminals, there is little change in the rate of rise or extent of the overshoot (Fig. 1D); in others, there is an increase in the rate of rise and overshoot as the impulse firing continues. An example of the latter, occurring during spontaneous bursting, is shown in Figure $1 C$. In this terminal, the duration at half-amplitude increased about 6-fold, one of the largest increases observed. Firing rate during the bursts reached a maximum of $12 /$ sec. In the example of Figure $1 D$, the duration increase was $30 \%$. The cxtent of broadening depends on both the rate of firing and number of impulses (Cooke, 1985). Terminals that showed broadening also showed changes of impulse duration when their resting potential was altered by current passing through the elec- trode, as previously described (Cooke, 1985).

Spike broadening was not observed in recordings from somata in normal saline. Impulse amplitude showed a marked decline at repetition rates greater than $1 / \mathrm{sec}$, as described previously. A small degree of broadening (30-100\%) was observed in all 4 axons tested for it. Since the axon penetrations were made less than $1 \mathrm{~mm}$ from the entry of the nerve into the SG, it is likely that the broadening represents an electrotonic reflection of more extensive broadening in the terminal.

Differences in ionic dependence and pharmacology of terminal, axon, and soma action potentials

\section{$\mathrm{Na}$ and $\mathrm{Ca}$ dependence}

Previous work has led to the conclusion that terminal action potentials include both $\mathrm{Na}$ and $\mathrm{Ca}$ inward current, while the
Figure 3. Regenerative response of a terminal in nominally $\mathrm{Na}$-free saline. Responses recorded intracellularly, all from the same terminal $(P$. vigil $)$, to depolarizing current passed through the recording electrode (current monitor, upper trace; differentiation of electrical record, lowest trace). Upper left frame, In normal saline (r.p. $-60 \mathrm{mV}$ ). Upper right, After 9 min perfusion with $\mathrm{Na}$ free, choline-substituted saline (r.p. -64 $\mathrm{mV})$. Lower left, During continued perfusion with $\mathrm{Na}$-free saline, $8 \mathrm{~min}$ after addition of $0.2 \mathrm{mM} \mathrm{CdCl}_{2}$ (r.p. -66 $\mathrm{mV})$. Lower right, Thirteen minutes after resuming normal perfusion (r.p. -62 $\mathrm{mV}$. Note continued presence of regenerative response in $\mathrm{Na}$-free saline but with reduced rate of rise and amplitude, and disappearance of active response after addition of $\mathrm{Cd}$. These effects were reversible.
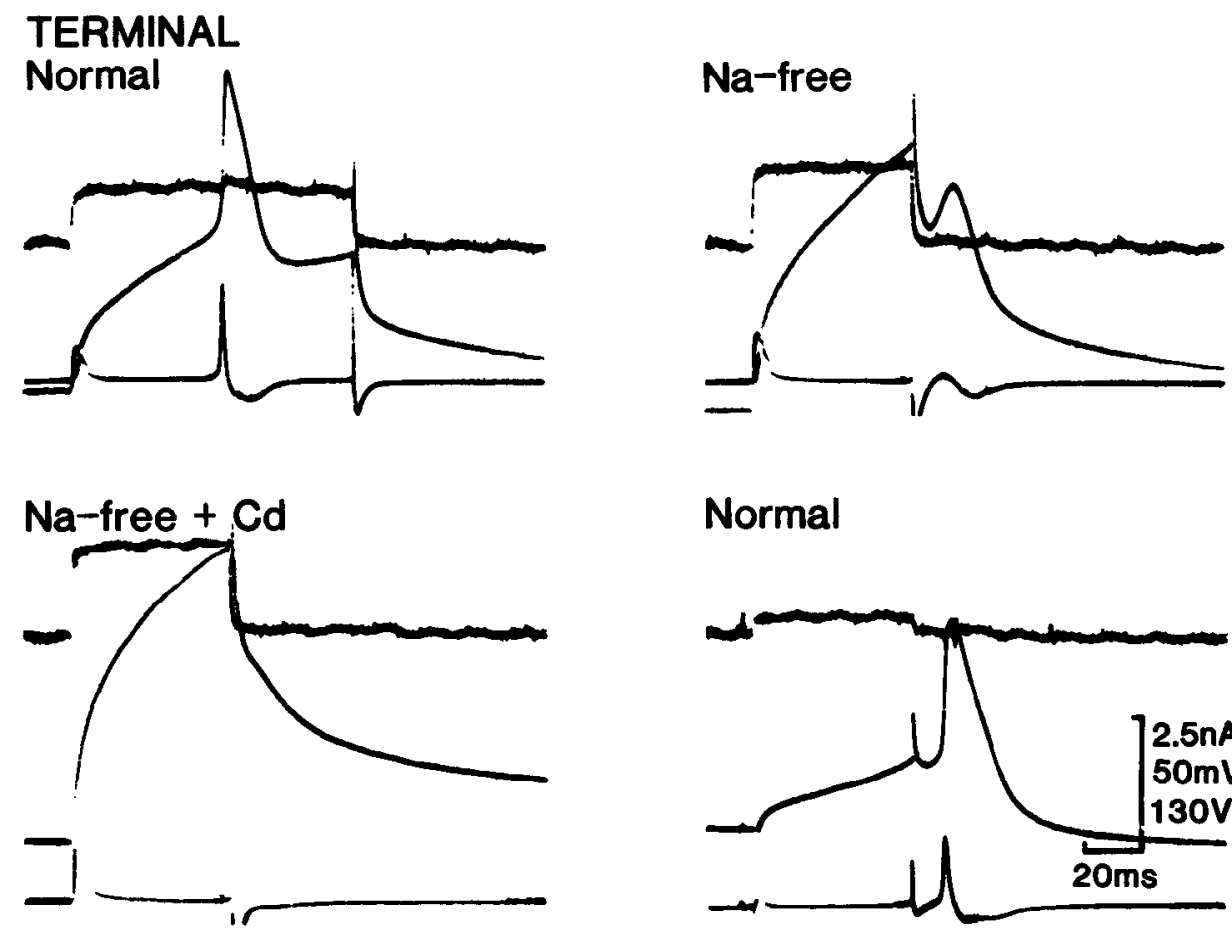


\section{TERMINAL}
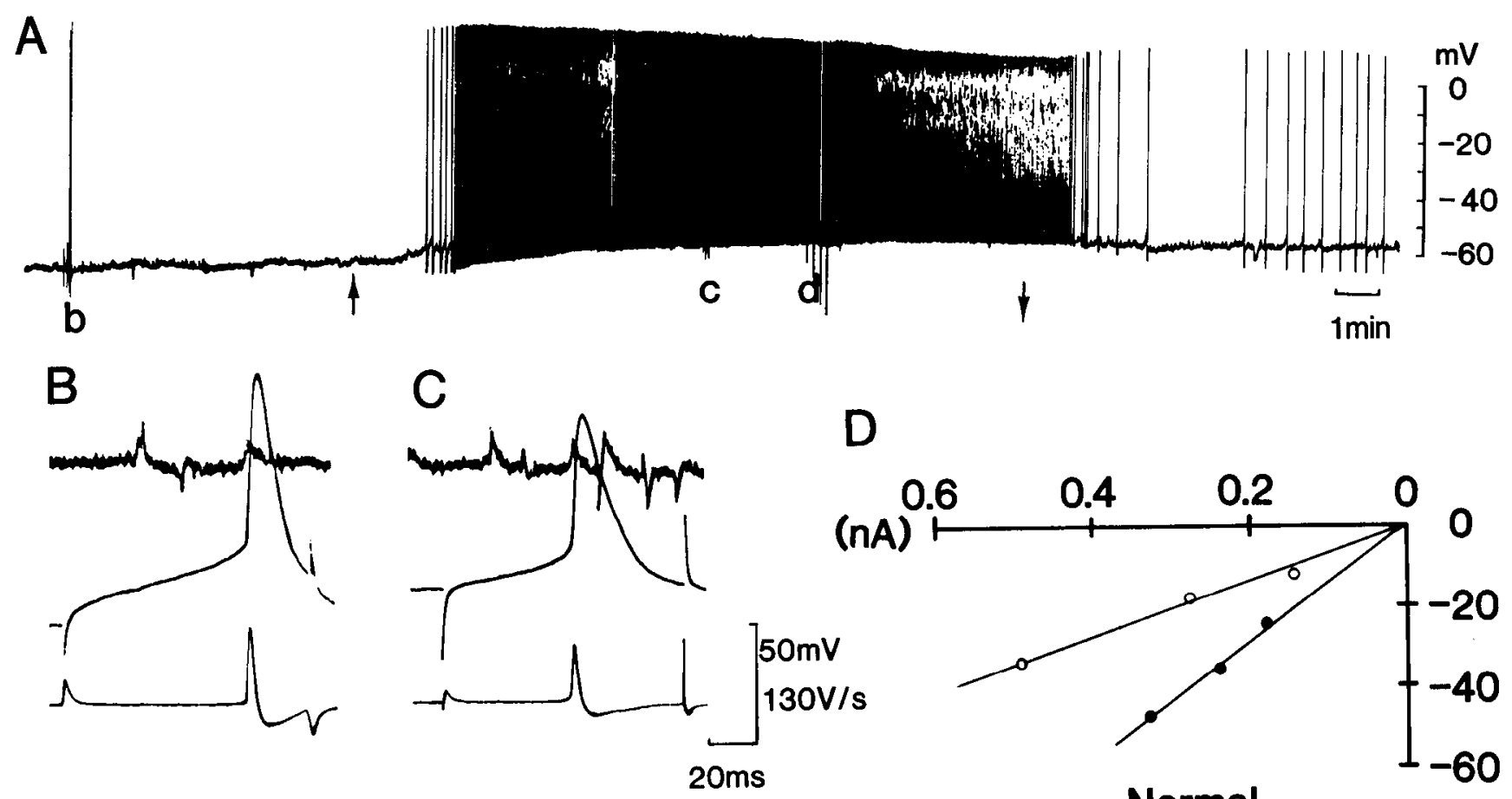

D

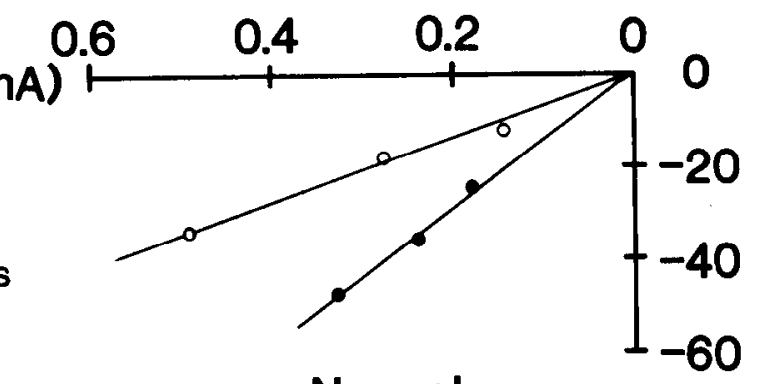

- Normal

- Ca-free

Figure 4. Effects of nominally Ca-free saline on terminal electrical activity. $A$, Continuous penwriter record of intracellularly recorded potential during switch to perfusion of the SG chamber with nominally Ca-free, Mg-substituted saline (upward arrow) and return to normal perfusion (downward arrow). The terminal, previously quiescent, depolarized slowly by about $10 \mathrm{mV}$ in low-Ca saline and exhibited regular spontaneous firing, reaching a rate of $1 / \mathrm{sec}$. The effects were slowly reversed upon returning to normal perfusion. Note progressive reduction of hyperpolarizing afterpotentials during low-Ca perfusion. $B$, Oscilloscope frame showing impulse evoked by depolarizing current through the electrode in normal saline (at $b$ in penwriter record). $C$, Impulse evoked during low-Ca perfusion (at $c$ ). Rate of rise and overshoot were reduced; falling phase shows flattened, slowed trajectory. Upward, time-locked deflection in extracellular trace indicates propagation proximally from terminal. $D$, Currentvoltage plot from measurements at the end of $0.8 \mathrm{sec}$ hyperpolarizing pulses given in normal saline (filled circles) and during low-Ca perfusion (at $d$, open circles). Note reduction in apparent input resistance (from 150 to $70 \mathrm{M} \Omega$ ) during low-Ca perfusion. $P$. vigil.

axon action potential is mediated primarily by Na. Dual mediation of soma action potentials and $\mathrm{Na}$ mediation of axonal action potentials were reported by Iwasaki and Satow (1971) for crayfish. Further evidence confirming these conclusions has been obtained in this study.

Terminals. Terminals were consistently found to be capable of responding to intracellular depolarizing current with regenerative action potentials during perfusion with nominally $\mathrm{Na}$ free saline (Fig. 3). Spontaneous activity and responses to axonal stimulation ceased in this saline. The rate of rise of action potentials in Na-free saline was less than one-third that in normal saline (Table 2; Fig. 5), and the impulses did not overshoot in 16 of 19 recordings. The response of the preparations to $\mathrm{Na}$ free saline and the form of terminal action potentials closely resemble those observed during perfusion with TTX-containing saline (Cooke, 1985), except that some hyperpolarization followed introduction of Na-free saline, whereas TTX caused little change of resting potential (Stuenkel, 1985).

Addition of $\mathrm{Cd}(0.2 \mathrm{~mm})$ to $\mathrm{Na}$-free saline reversibly blocked the remaining regenerative responses (Fig. 3; see also Stuenkel, 1985). These observations support the suggestion that action potentials in $\mathrm{Na}$-free saline are produced by $\mathrm{Ca}$-inward current.

In all preparations, introduction of saline from which $\mathrm{Ca}$ had been omitted ("Ca-free" saline) led to an increase of spontaneous activity. In about half of the terminals, there was a slow, marked depolarization that led to inactivation when the resting potential became less than $-35 \mathrm{mV}$. In these cases, active responses could usually be observed if the membrane was held more polarized by current passing. In the other terminals, less extensive depolarization occurred during $\mathrm{Ca}$-free perfusion and spontaneous firing continued. An example of a terminal showing moderate depolarization during perfusion with $\mathrm{Ca}$-free saline is shown in Figure 4. A change in the impulse waveform occurred, some of which can be attributed to depolarization and repetitive activity on the basis of observing that hyperpolarization (and subsequent reduction of spontaneous impulse firing rate) led to restoration of the overshoot and reduction of the impulse duration to values close to those in normal saline. Other changes, such as a flattened, slowed trajectory of the falling phase and reduction of the hyperpolarized afterpotential are the result of the reduced Ca saline, as previously described (Cooke, 1985). In the terminal illustrated in Figurc 4, hyperpolarizing current pulses were injected to assess the apparent input resistance in normal and in $\mathrm{Ca}$-free saline. There was a marked decrease of apparent input resistance (from 150 to $70 \mathrm{M} \Omega$ ) during perfusion with $\mathrm{Ca}$-free saline. The relatively linear current-voltage plot indicates that this cannot be attributed directly to the reduced resting potential. It also cannot be attributed to a deficiency of divalent cations in the saline, since $\mathrm{Mg}$ was substituted for the $\mathrm{Ca}$ omitted.

The extent to which changes in the rate of rise of responses 


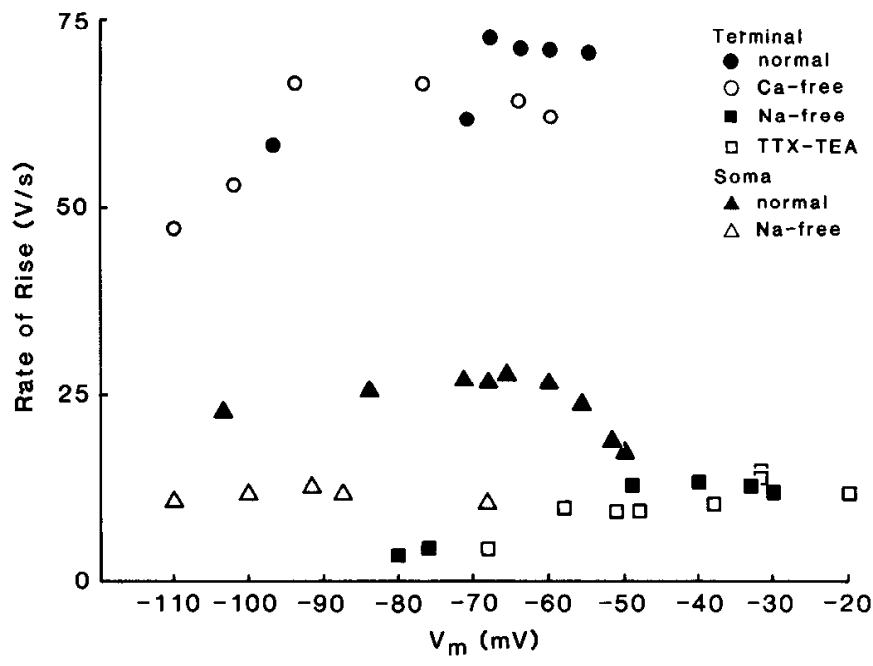

Figure 5. Rates of rise of terminal and soma action potentials in normal and altered salines plotted against holding potential. Data shown were obtained from a single terminal recorded from a preparation in which the axon tract had been ligated near the SG and from a single soma in another preparation similarly ligated (both $C$. carnifex). Impulses were initiated by depolarizing current passed through the electrode. Note that in normal saline, the terminal action potential had a rate of rise nearly 3 times that of a soma; removal of $\mathrm{Ca}$ affected the rate of rise of the terminal impulse relatively little, while the presence of TTX or removal of $\mathrm{Na}$ reduced the rate of rise of both terminal and soma action potentials to ca. $12 \mathrm{~V} / \mathrm{sec}$. In the terminal in Na-free or TTX-TEA saline, depolarization did not further depress the rate of rise.

should be attributed to alterations of the saline ionic composition or are subsequent to changes of the resting potential may be evaluated from the data presented in Table 2 and plotted in Figure 5. The graph includes measurements from a single terminal (and from a soma, see below) recorded after ligating the

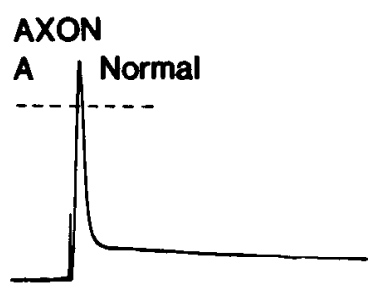

B Na-free

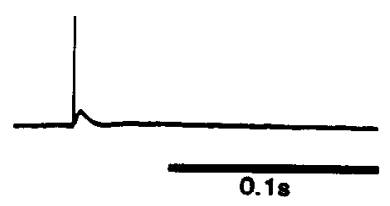

C Na-free

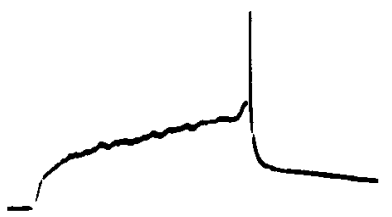

D Normal

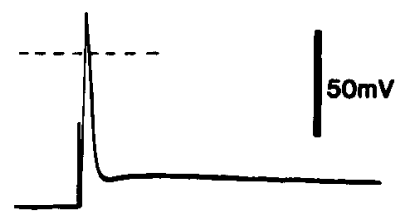

Figure 6. $\mathrm{Na}$ dependence of axonal action potential. All recordings from an axon penetrated ca. $0.5 \mathrm{~mm}$ from entry of the axon tract into the SG $(P$. vigil). $A$, Action potential in normal saline evoked by extracellular stimulation of the axon tract. Note long, depolarized afterpotential (r.p. $-84 \mathrm{mV}$ ). B, After 8 min perfusion of the SG chamber with nominally $\mathrm{Na}$-free saline. Extracellular stimulation failed to elicit an action potential. $C$, After 9 min of $\mathrm{Na}$-free perfusion. Passage of depolarizing current through the recording electrode $(1.5 \mathrm{nA})$ failed to evoke an active response (r.p. in $B$ and $C,-74 \mathrm{mV}$ ). $D$, Action potential in response to extracellular stimulation $3 \mathrm{~min}$ after returning to perfusion with normal saline (r.p. $-74 \mathrm{mV}$ ). Depolarized afterpotential was present despite reduced resting potential.
SOMA

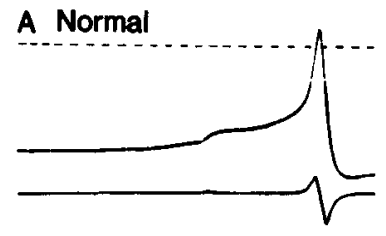

B Ca-free

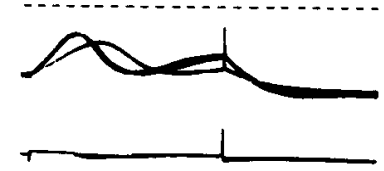

C Na-free
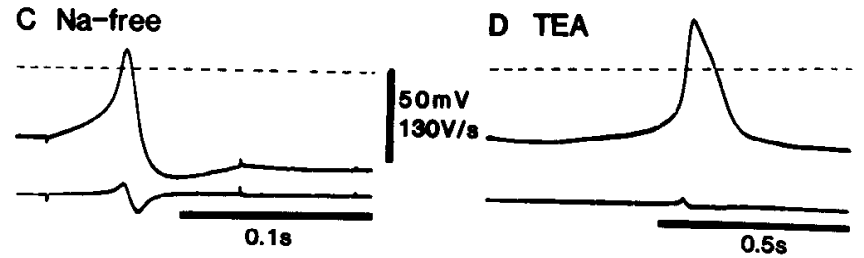

Figure 7. Effects of altered salines on action potentials of a soma. All records from the same cell (C. carnifex). Electrical differentiation of the intracellular record shown in the lower traces; broken line indicates 0 $\mathrm{mV}$. $A$, Spontaneous action potential in normal saline (r.p. $-56 \mathrm{mV}$ ). $B$, Three superimposed responses to depolarizing current recorded 7 min after beginning perfusion of the XO chamber with nominally $\mathrm{Ca}$ free, Mg-substituted saline (r.p. $-36 \mathrm{mV}$ ). The low-Ca saline led to depolarization and spontaneous activity, which ceased when depolarization reached $-30 \mathrm{mV}$. Effects were reversed on returning to normal perfusion. Similar effects were observed during subsequent perfusion with nominally $\mathrm{Ca}$-free, Na-substituted saline. $C$, Action potential evoked by depolarizing current 9 min after introducing nominally $\mathrm{Na}$-free, choline-substituted perfusate. Cell held at $-36 \mathrm{mV}$ by passing current to allow comparison with B. $D$, "Spontaneous" impulse recorded 7 min after beginning perfusion with saline containing $50 \mathrm{~mm}$ TEA (cell held at $-36 \mathrm{mV}$ by current passing). Note slower time base and greatly increased duration of the action potential.

axon tract; current was passed to alter the holding potential. It is clear that the rate of rise values in normal and $\mathrm{Ca}$-free saline as compared with $\mathrm{Na}$-free saline fall in entirely different ranges, being large in the presence of $\mathrm{Na}$ and much reduced in its absence. They were not greatly altered by removal of $\mathrm{Ca}$ in the presence of normal $\mathrm{Na}$. The values for rate of rise are not very sensitive to membrane holding potential over the range -50 to $-80 \mathrm{mV}$, which includes the normally observed resting potentials. Thus, the reduced rate of rise observed in reduccd Nasalines is the result of the lack of $\mathrm{Na}^{+}$, and not of changes in resting potential. Overshoot is reduced or absent in Na-deficient or TTX-containing saline and little affected by Ca-deficient salines per se.

Axons. Intracellular recordings were obtained from the group of 4-6 large axons visualizable in $P$. vigil preparations. The

Table 2. Effects of altered salines on rates of rise and fall of terminal and somata action potentials

\begin{tabular}{llllll} 
& \multicolumn{2}{l}{$\begin{array}{l}\text { Maximum rate of rise } \\
\text { (V/sec) }\end{array}$} & & \multicolumn{2}{l}{$\begin{array}{l}\text { Maximum rate of fall } \\
\text { (V/sec) }\end{array}$} \\
\cline { 2 - 3 } Saline & Terminal & Soma & & Terminal & Soma \\
\hline Normal & $81.7 \pm 5.0$ & $36.1 \pm 5.6$ & & $28.6 \pm 2.9$ & $30.5 \pm 7.9$ \\
& $(15)$ & $(3)$ & & $(15)$ & $(3)$ \\
Ca-free & $75.1 \pm 7.3$ & $a$ & & $18.3 \pm 1.4$ & $a$ \\
& $(4)$ & $(3)$ & & $(4)$ & $(3)$ \\
Na-free & $15.5 \pm 1.3$ & $12.0 \pm 2.9$ & & $12.8 \pm 1.5$ & $16.9 \pm 6.9$ \\
& $(13)$ & $(3)$ & & $(13)$ & $(3)$
\end{tabular}

Values given are means $\pm \mathrm{SD}$; number of observations in parentheses.

${ }^{a}$ The somata depolarized and did not exhibit impulses. 

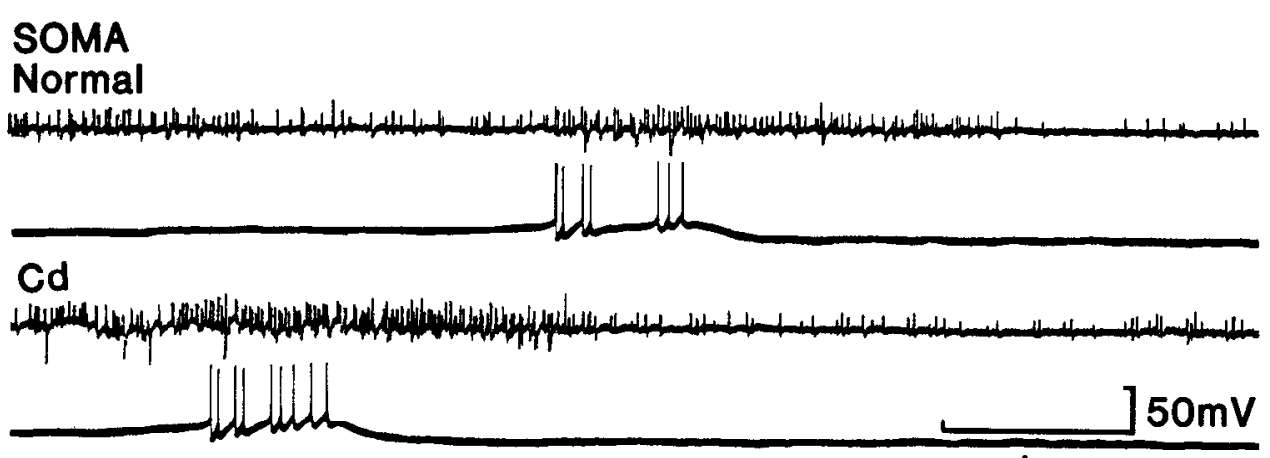

$1 \mathrm{~s}$
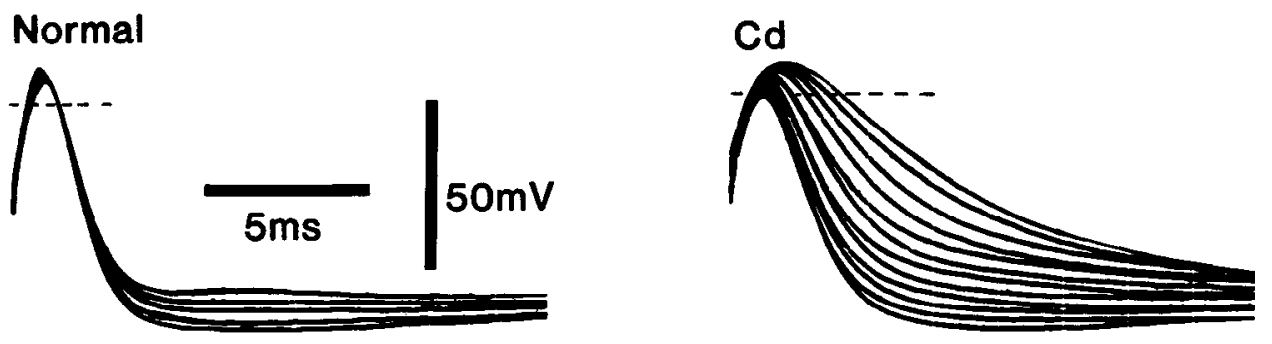

Figure 8. Effects of Cd on action potential duration of a spontaneously bursting soma. Simultaneous recording (moving film, unswept spots) of spontaneous activity in the axon tract (top trace; upward deflection, proximal to distal propagation through the Vaseline barrier) and in a soma ( $P$. vigil, r.p. -60 to $-62 \mathrm{mV}$ ). The second pair of traces was recorded $12 \mathrm{~min}$ after beginning perfusion of the $\mathrm{XO}$ chamber with saline containing $0.9 \mathrm{mM} \mathrm{CdCl}_{2}$. Frames below show impulses of a spontaneous burst superimposed: in normal saline (left), and $7 \mathrm{~min}$ after beginning $\mathrm{Cd}$ perfusion (right). Note that increased extracellular activity coincided with the intracellularly recorded bursts; the impulses of a burst were superimposed on a depolarized plateau, which outlasted the impulse firing; an increased number of impulses occurred in the burst during Cd perfusion (burst frequency was also increased). Spike broadening was observed during $\mathrm{Cd}$ perfusion but was absent in normal saline. Cd effects were fully reversible. See also Figure $14 A$. recordings provide direct confirmation of the $\mathrm{Na}$ dependence of the axonal action potential. Records from an axon before, during, and after perfusion with nominally Na-free saline are shown in Figure 6. In $\mathrm{Na}$-free saline the axon failed to exhibit a regenerative response, either to extracellular stimulation or to intracellularly applied depolarizing current. Responsiveness returned immediately upon reintroducing normal saline.

Intracellular recording from an axon during perfusion of $\mathrm{Ca}$ free saline showed no noticeable change in the waveform (not illustrated).

Somata. Responses recorded from somata proved to have both $\mathrm{Na}$ and $\mathrm{Ca}$ dependence (as in crayfish; Iwasaki and Satow, 1971 ) in those neurons exhibiting overshooting action potentials. As discussed above, not all somata exhibit overshooting potentials, and some penetrations with stable resting potentials exhibited no responses. The experiments to be discussed here and below concerning the effects of ionic manipulations or pharmacological agents were done on somata exhibiting overshooting impulses.

All of the somata tested with perfusion of nominally $\mathrm{Na}$-free (5) and Ca-free (3) salines continued to show regenerative responses in each saline. Records from 1 soma are shown in Figure 7. In this soma, perfusion of $\mathrm{Ca}$-free saline led to major depolarization (from $-56 \mathrm{mV}$ in normal saline to $-30 \mathrm{mV}$ ). The depolarization required much longer than replacement of the chamber saline with Ca-free saline, and impulse firing, at an increasing rate, accompanied the initial depolarization. The impulses then became attenuated and finally failed. The same result was seen whether $\mathrm{Ca}$ was replaced by addition of $\mathrm{Mg}$ (as in Fig. 7) to maintain divalent cation concentration constant or was replaced by $\mathrm{Na}$. The decreased impulse amplitude with depolarization could be counteracted by passing current to repolarize the soma. In the other 2 somata tested, introduction of Ca-free saline led to depolarization of less than $10 \mathrm{mV}$ and to accelerated rates of spontaneous impulse firing that reached a stable rate and continued until normal perfusion was restored. The impulses exhibited little change of form. As in the case of terminals, somata perfused with $\mathrm{Ca}$-free saline showed a decrease in apparent input resistance. The effects of $\mathrm{Ca}$-free saline were reversible, provided the period in $\mathrm{Ca}$-free saline was kept to less than $20 \mathrm{~min}$.

As in terminal recordings, the regenerative potentials recorded from somata during perfusion in the $\mathrm{Na}$-free saline (Fig. 7) do not overshoot and have rates of rise that are about one-third as fast as in normal saline (Table 2). Data from a soma tested in normal and $\mathrm{Na}$-free salines over a range of membrane holding potentials are summarized in Figure 5 together with comparable data from a terminal. In the preparation providing data for Figure 5 the axon tract was ligated near the SG. The interpretation that depolarization, rather than absence of $\mathrm{Ca}$, reduces the active response in $\mathrm{Ca}$-free salines is consistent with the effect of depolarization in reducing the rate of rise (Fig. 5).

\section{Effects of cadmium}

Terminals. The elimination of regenerative responses of terminals in $\mathrm{Na}$-free saline by addition of $\mathrm{Cd}$ has already been discussed. Added to normal saline, Cd (0.2-1.2 mM) had little effect on the form of spontaneous or evoked terminal action potentials; in 1 of the 10 recordings, the afterhyperpolarization was reduced (cf. Stuenkel, 1985).

Somata. The effects of adding Cd to normal saline were more marked on somata having overshooting action potentials than on terminals. In 1 preparation, an intracellular recording was made simultaneously from a terminal and soma during Cd perfusion of both. Cd perfusion usually (4 of 5 preparations) led to a small, sustained depolarization (up to $5 \mathrm{mV}$ ). Overshoot was reduced, impulse duration was increased by $25 \%$ or more in spontaneously firing preparations, and hyperpolarizing afterpotentials were reduced. These effects were not influenced by repolarizing to the former resting level. Somata that did not exhibit impulse broadening during repetitive firing in normal saline did so in the presence of $\mathrm{Cd}$ (Fig. 8). The effects of $\mathrm{Cd}$ were rapidly reversed upon resuming perfusion with normal saline. 


\section{TERMINAL}

A Normal
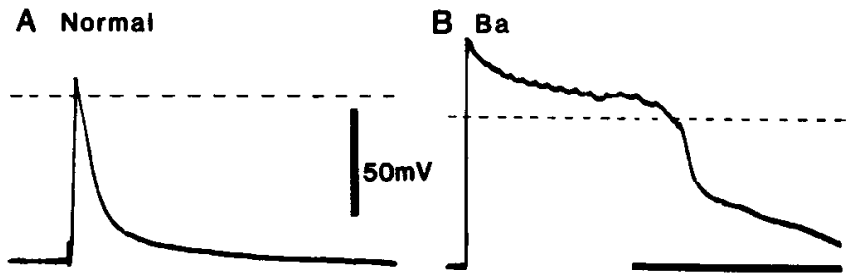

$0.5 \mathrm{~s}$

C Normal

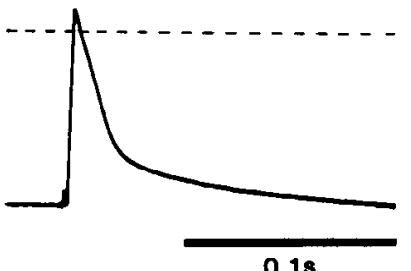

D Ba, Ca-free

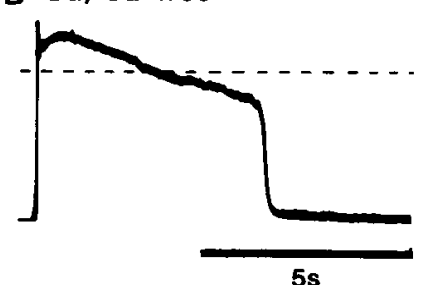

5s
Figure 9. Effects of $\mathrm{BaCl}_{2}$ on the terminal action potential. All records from the same terminal $(P$. vigil); impulses were evoked by stimulation of the axon tract. $A$, In normal, $\mathrm{SO}_{4}$-free saline (r.p. $-76 \mathrm{mV}$ ). $B$, Twelve minutes after beginning perfusion of the $S G$ chamber with saline containing $50 \mathrm{~mm} \mathrm{BaCl}$, normal $\mathrm{Ca}$ (r.p. $-70 \mathrm{mV}$ ). $C$, After return to normal, $\mathrm{SO}_{4}$-free perfusion (r.p. $-82 \mathrm{mV}$; calibration applies also to $A$ ). $D$, Twelve minutes after heginning perfusion of the $\mathrm{SG}$ chamber with $50 \mathrm{mM} \mathrm{BaCl}_{2}$, Ca-free saline (r.p. $-70 \mathrm{mV}$ ). In Ba-containing salines, the overshoot increased and a long, depolarized shoulder followed. In the $\mathrm{Ca}$-free Ba saline, the shoulder lasted longer than $5 \mathrm{sec}$ (note changes of time base).

\section{Effects of barium}

Terminals. In many tissues having voltage-dependent $\mathrm{Ca}$ conductance, the addition of $\mathrm{Ba}$ to the saline results in exaggerated regenerative responses, which have been attributed to aug- mented current through $\mathrm{Ca}$ channels, as well as to Ba block of, or failure to activate, outward conductances (Gorman and Hermann, 1979; Hagiwara and Byerly, 1981). This proved true in recordings from terminals and somata of these neurosecretory cells. Axonal recordings were not obtained. Figure 9 presents records, typical of 6 preparations tested, obtained from a terminal before and after the addition of $50 \mathrm{mM} \mathrm{BaCl}_{2}$ to the saline perfusing the SG chamber. Potentials having a larger overshoot and a sustained shoulder lasting longer than $0.5 \mathrm{sec}$ occurred spontaneously. Oscillations appearing during the plateau may represent axonal impulse firing. Oscillations were also observed in a preparation mounted without Vaseline. If $\mathrm{Ba}$ was added in a Ca-free saline (tested in 2 preparations), the duration of the spontaneous potentials was even longer, lasting several seconds. In the preparation illustrated, there was a $12 \mathrm{mV}$ depolarization of the resting potential upon introduction of the $\mathrm{Ca}$-free, $\mathrm{Ba}$ saline. Unlike the normal Ca-50 mм Ba saline, introduction of the $\mathrm{Ca}$-free $\mathrm{Ba}$ saline to the $\mathrm{SG}$ chamber consistently increased the level of spontaneous activity as monitored with the extracellular elcctrodes. Hyperpolarizing afterpotentials were absent in Ba-containing salines. The effects of $\mathrm{Ba}$ were partially reversed upon resumption of normal saline perfusion.

Somata. A few intracellular recordings from somata were obtained during perfusion of the XO chamber with $50 \mathrm{~mm} \mathrm{Ba}$ (normal $\mathrm{Ca}$ ) saline. In these cases, the duration of the action potential was approximately doubled. One soma that did not exhibil overshooting action potentials in normal saline did so in the Ba saline. Extracellularly recorded spontaneous activity was consistently increased by introduction of $\mathrm{Ba}$ saline into the $\mathrm{XO}$ chamber.

\section{Effects of TEA}

Terminals. TEA is widely known as an inhibitor of delayed, voltage-dependent $K$ conductance, and it has species-dependent

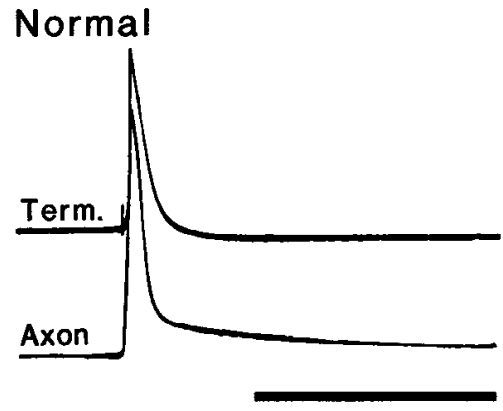

$0.1 \mathrm{~s}$
TEA
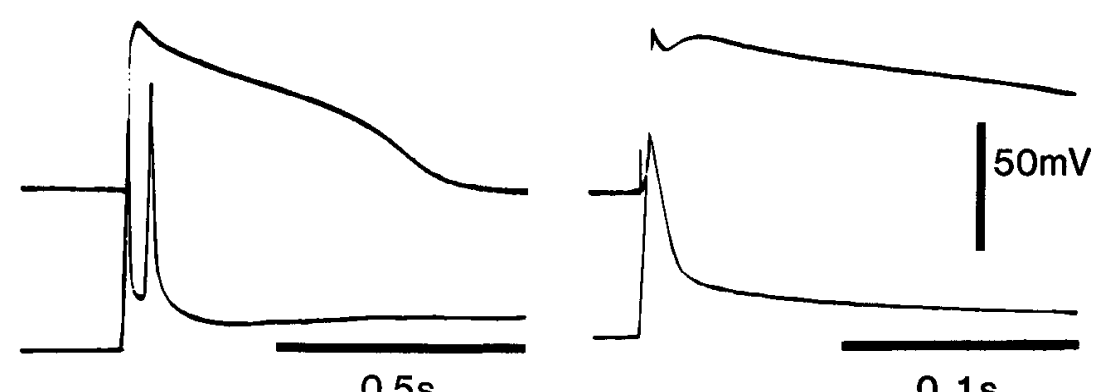

$0.1 \mathrm{~s}$

TEA

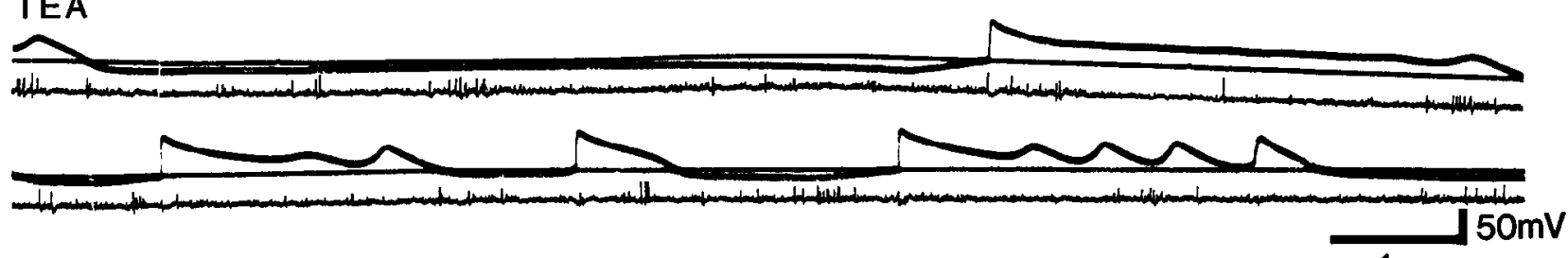

$1 \mathrm{~s}$

Figure 10. Effects of TEA on terminal and axonal action potentials. Frames show action potentials evoked by stimulation of the axon tract recorded simultaneously from a terminal (upper traces) and an axon (lower traces). Left, In normal saline. Note depolarized afterpotential in the axon (C. carnifex, r.p. terminal, $-60 \mathrm{mV}$; axon, $-88 \mathrm{mV}$ ). Middle, Seven minutes after beginning perfusion of the SG chamber with saline containing $50 \mathrm{mM}$ TEA (note slower time base). Right, After $9 \mathrm{~min}$ of TEA perfusion. Note small increase in axon impulse duration and presence of depolarized plateau in terminal. Below, Spontaneous activity rccorded 13 min after beginning TEA perfusion (moving film, unswept oscilloscope spots; the 2 lines of records are continuous; lower trace is an extracellular recording form the axon tract). The terminal showed spontaneous depolarizations followed by sustained, fluctuating plateaus. The axon recording shows no spontaneous activity. 
inhibitory effects on other $\mathrm{K}$ conductances as well (Stanfield, 1983). The use of TEA has often aided in the demonstration of voltage-dependent $\mathrm{Ca}$ current by eliminating the outward $\mathrm{K}$ current, which may develop on a similar time course. When 50 mM TEA was applied to terminals of the crab neurosecretory neurons, it increased the amplitude and duration of the spontaneous or evoked terminal potentials significantly. Examples of the effects of TEA are shown in Figures 10 and 11. In all terminals examined in TEA saline the extent of overshoot increased, a long shoulder or plateau developed during the falling phase of the potential, and hyperpolarizing afterpotentials were reduced, and occasionally eliminated. In some terminals a notch separating the initial depolarizing peak from a second peak from which the plateau developed was clearly seen (Fig. 10). The initial peak may be interpreted as representing a $\mathrm{Na}$-dominated action potential, since it was eliminated by addition of TTX $\left(3 \times 10^{-7} \mathrm{M}\right)$ to the TEA saline and was absent in nominally Na-free TEA saline (Fig. 11). The rates of rise observed in TEA in the presence of TTX were very similar to those seen in $\mathrm{Na}$ frec saline in the absence of TEA (Fig. 5).

A number of observations were obtained bearing on the nature of the conductance responsible for the long depolarized shoulder of responses in the presence of TEA. As previously mentioned, the shoulder is observed in reduced-Na saline and is unaffected by addition of TTX. In a nominally Ca-free saline (Fig. 11), the initial depolarization immediately declined to a sustained plateau about $15 \mathrm{mV}$ depolarized from baseline lasting, in this example, $10 \mathrm{sec}$. Oscillations began to appear during the $3 \mathrm{sec}$ preceding repolarization. Addition of $\mathrm{Cd}(0.2 \mathrm{mM})$ to otherwise normal TEA saline had no clear effect on the plateau or shoulder of evoked responses (not illustrated). However, addition of $\mathrm{Cd}$ to a nominally $\mathrm{Na}$-free TEA saline reduced the initial depolarization to about half and the duration of the response to about a tenth that of the response in the absence of $\mathrm{Cd}$ (4 preparations tested). One interpretation consistent with these observations is that the conductance responsible for the sustained shoulder is a relatively nonspecific one for cations.

Axons. Figure 10 illustrates the marked difference in the effects of TEA on terminals and on axons. Simultaneous intracellular recordings are shown from a terminal and from an axon (not of the same neuron, however) during introduction of $5 \mathrm{~mm}$ TEA to the saline perfusing the SG chamber. In this preparation, the terminal exhibited not only long-duration action potentials, but the development of depolarized plateaus underlying extended bouts of impulse firing (bursts). Some of these impulses, in turn, included an extended shoulder lasting several seconds, on which slow oscillations were sometimes present. The TEA effects were slowly reversible.

The record from the axon shown in Figure 10, by contrast, shows at most a doubling of the duration of its action potential. To what extent this may have been influenced by electrotonic spread from terminals is unknown. The recording is typical of responses seen in 3 of 4 axonal recordings. The fourth showed responses to TEA perfusion of the type observed in terminals. The double impulse seen in response to a short $(0.1 \mathrm{msec})$ extracellular stimulus of the axon tract (Fig. 10, middle frame) in the presence of TEA suggests the possibility that the second impulse was initiated by the sustained depolarization of its terminal.

Somata. In recording from somata during perfusion of TEAcontaining saline on the $\mathrm{XO}$, a marked increase of the impulse duration was observed (up to about 10-fold); however, this was much less than in terminal recordings, where impulse durations
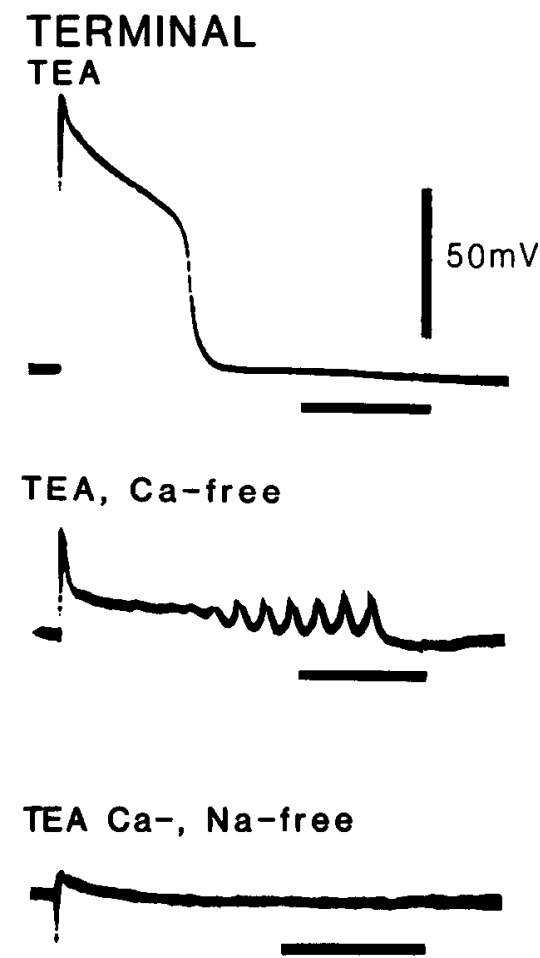

Figure 11. Ca dependence of the TEA-induced plateau in a terminal. Action potentials evoked by axonal stimulation recorded from a terminal (C. carnifex). Top, nine minutes after beginning perfusion with saline containing $50 \mathrm{~mm}$ TEA. Middle, During continued perfusion with TEA, $6 \mathrm{~min}$ after introducing nominally Ca-free, $50 \mathrm{~mm}$ TEA saline. Note reduced amplitude of plateau but increased duration. Bottom, five minutes after switch from Ca-free TEA saline to nominally Ca-free and $\mathrm{Na}$-free TEA saline. Impulse initiation was blocked. Resting potential held at $-60 \mathrm{mV}$ throughout by current passing. Time bars: $0.4 \mathrm{sec}$, top and bottom; 2 sec, middle.

increased 50-fold. A separation of early and late peaks was not seen. An example of an impulse recorded in TEA from a soma is given in Figure $7 D$.

\section{Effects of quinine}

Terminals. Quinine $(0.3 \mathrm{~mm})$ was tested for its effects on terminal and soma action potentials becausc it has been found to cause a selective inhibition of late Ca-mediated $\mathrm{K}$ conductance in barnacle neurons (Hanani and Shaw, 1977). There were no clear effects on the form of terminal action potentials in 2 of 3 preparations. In 1 case (Fig. 12), the duration of the impulse increased $20 \%$ at half-amplitude. There was no effect on the amplitude of the hyperpolarizing afterpotentials.

Somata. By contrast, in recordings from somata showing overshooting action potentials (4 preparations, Fig. 12), addition of quinine in each case led to a slow depolarization of the baseline of up to $5 \mathrm{mV}$ that was accompanied by an increased rate of spontaneous firing and a reduction in the rate of rise, overshoot, rate of repolarization, and amplitude of the hyperpolarizing afterpotential of the impulse (Fig. 12). The effects of quinine were irreversible, although some recovery (slowing) of the spontaneous firing rate followed the return to perfusion with normal saline.

\section{Effect of pharmacological agents on burst formation}

$T T X$. As described above, patterned impulse firing or bursting was often seen in intracellular recordings from terminals or 

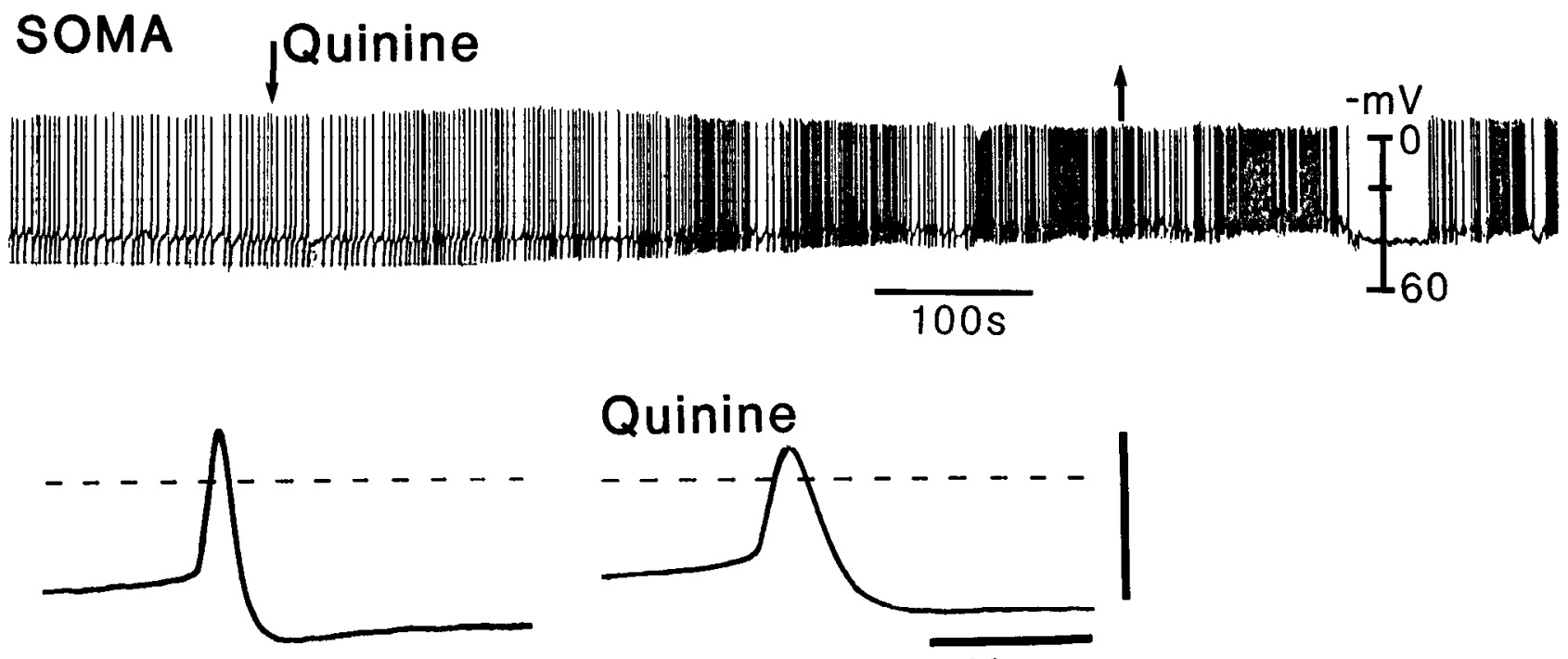

Quinine

\section{TERMINAL}

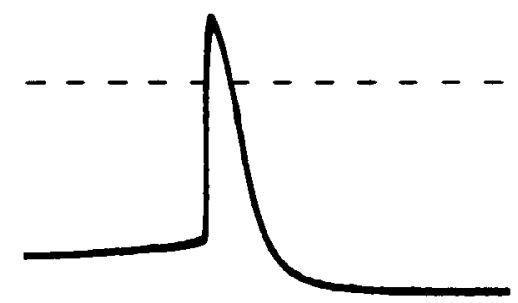

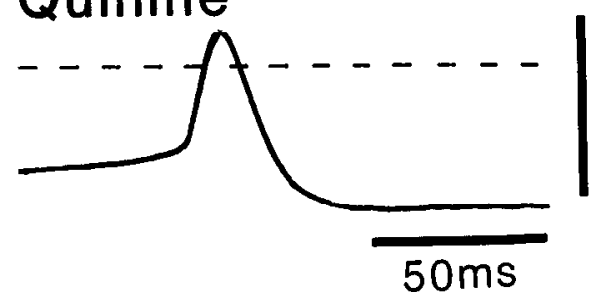

Quinine

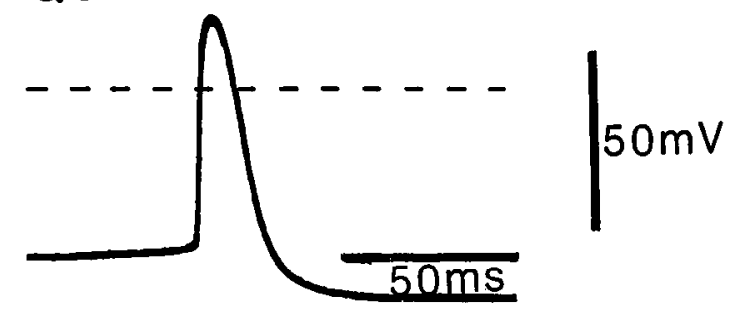

Figure 12. Effects of quinine $(0.3 \mathrm{~mm})$ on electrical activity of a soma and terminal. Top, Penwriter record of elcctrical activity of a soma (C. carnifex) during switch to perfusate containing $0.3 \mathrm{~mm}$ quinine (downward arrow; both chambers, no Vaseline present) and return to normal perfusion (upward arrow). An increase in frequency of spontaneous impulse firing occurred and slowly reversed on return to normal perfusion. Reduction of hyperpolarizing afterpotentials occurred and was not reversed. Center, Action potential form before and during quinine perfusion (from same soma). Rate of rise, overshoot, rate of repolarization, and afterpotential were reduced. These changes were not reversible. Bottom, Action potentials of a terminal (C. carnifex) recorded before and after $15 \mathrm{~min}$ of quinine perfusion (see Fig. 14C2). Half-amplitude duration increased ca. $20 \%$ ( 2 other preparations showed no changes). The change was not reversed. Broken lines indicate $0 \mathrm{mV}$.

somata as a train of impulses arising from a depolarized plateau. In some preparations, the initiation of the plateau appeared to precede the commencement of impulse firing, and repolarization to follow the cessation of firing. Evidence suggesting that the plateau potential may represent a regenerative response separable from action potentials was obtained from 29 preparations (19 terminal, 2 axon, and 8 soma recordings) in which bursts could be evoked by single brief stimuli applied to the SG nerve.
Figure 13. Evoked bursting and effects of TTX. Penwriter records from a terminal (C. carnifex) having a high resting potential and showing no spontaneous firing. Brief $(0.1 \mathrm{msec})$ stimuli were applied across the Vaseline bridge (downward artifacts). A, The first stimulus elicited a small depolarization, the next (at increased intensity) elicited a sustained depolarization (plateau potential) on which a burst of impulse firing was superimposed. Note that the plateau outlasts the impulse firing and is followed by hyperpolarization. $B$, Record after $8 \mathrm{~min}$ perfusion of the SG chamber with saline containing $3 \times$ $10^{-7} \mathrm{M}$ TTX. A plateau was initiated by extracellular stimulation. The small superimposed deflections are interpreted as impulses initiated by the axon in the XO chamber, which continued to be perfused with normal saline. A second stimulus gave rise to an abbreviated plateau without impulse activity. See also Figure 14B.

\section{Terminal} $-m V$

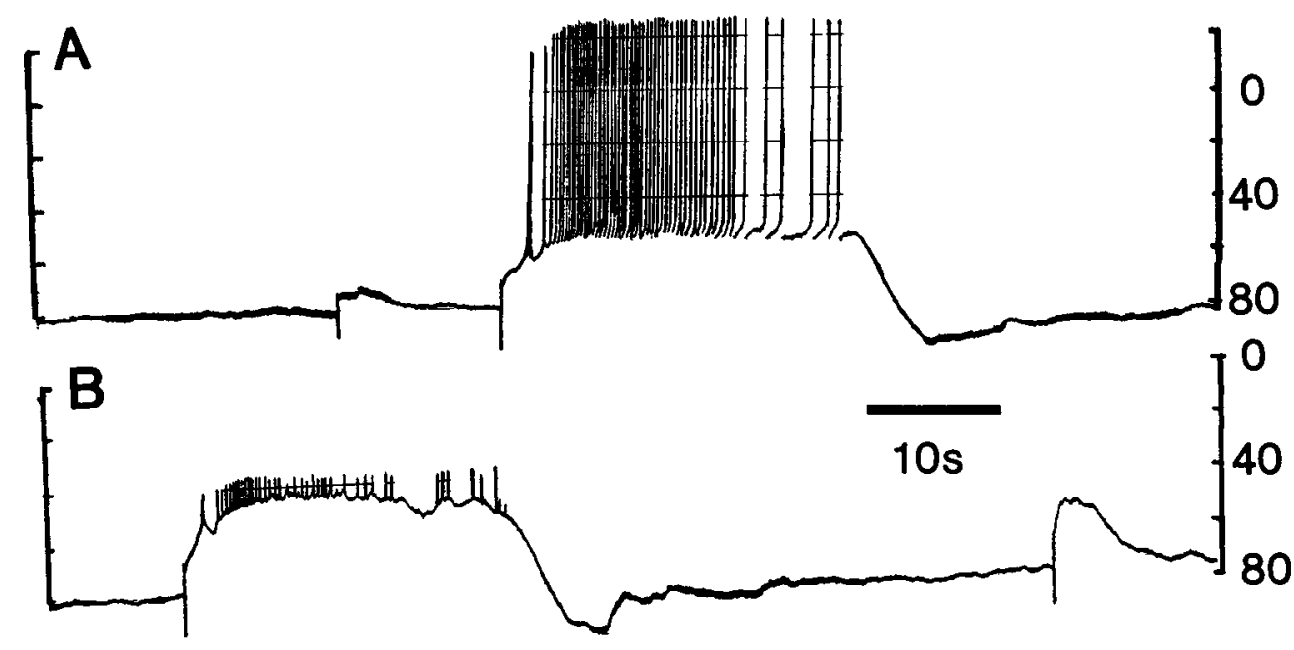




\section{Terminal}
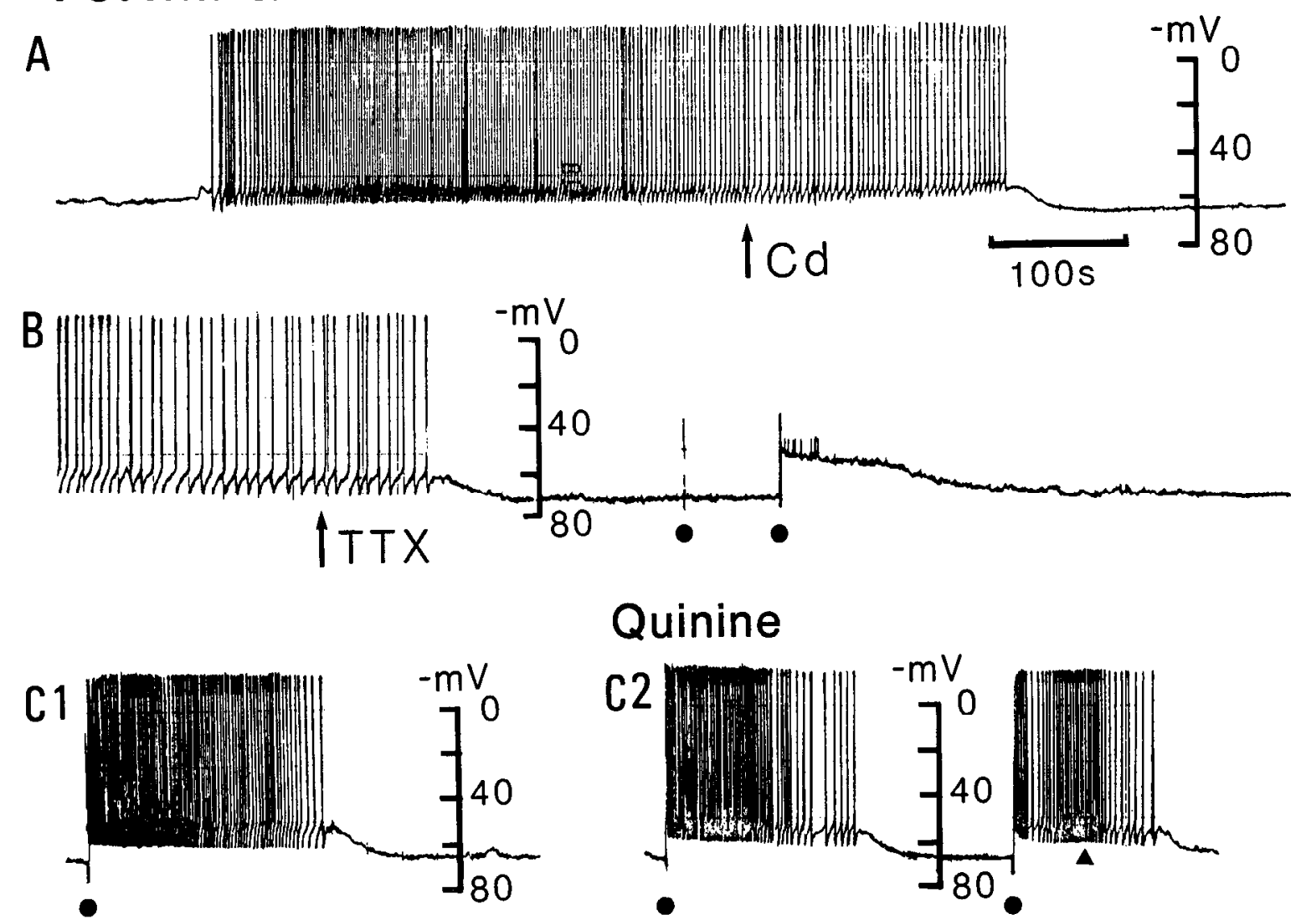

\section{Quinine}

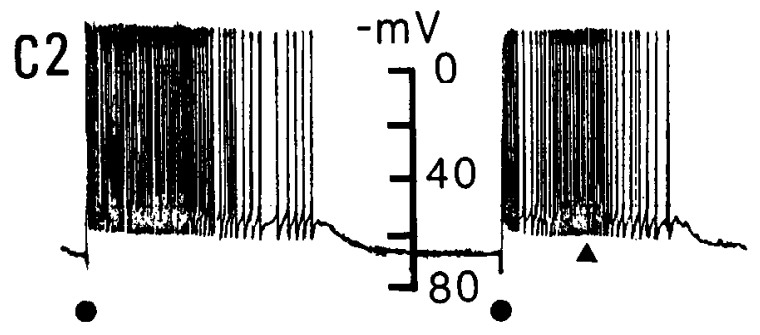

Figure 14. Resistance of plateau potentials to conductance blockers. Penwriter records, all from the same terminal (C. carnifex). The preparation was mounted without Vaseline; changes in perfusate composition were made simultaneously in both chambers. $A$, Example of a long (ca. 10 min) burst superimposed on a plateau potential. These occurred spontaneously with about 15 min interburst intervals. A switch to perfusate containing $0.2 \mathrm{mM} \mathrm{CdCl}_{2}$ (arrow) reduced the intraburst firing frequency and the hyperpolarizing afterpotentials of individual impulses but left burst pattern unaffected (see Fig. 8). B, One hour after restoring normal perfusion (Cd effects were rapidly reversed), a switch to perfusate containing $1.5 \times 10^{-7} \mathrm{M}$ TTX was made during a spontaneous burst. The second, more intense extracellular stimulus $(\theta)$ to the axon tract evoked a plateau potential. The small, superimposed upward deflections were absent in subsequent responses and no spontaneous activity occurred during TTX perfusion. $C 1$, Burst superimposed on a plateau potential elicited by a stimulus to axon tract as in $B$, recorded $1 \mathrm{hr}$ after resuming perfision with normal saline. C2, Bursts as in $C 1$, recorded 10 min after switching to perfusate containing $0.3 \mathrm{~mm}$ quinine. Impulse at the triangle (A) shown in Figure 12.

TTX $\left(1.5 \times 10^{-7} \mathrm{M}\right)$, added to the perfusate of the chamber from which the intracellular recording was being taken (terminal or soma), blocked impulse initiation by such stimuli but left a reponse consisting of a sudden $20 \mathrm{mV}$ depolarized shift that was sustained for periods of seconds to minutes, depending on the individual preparation, and ultimately terminated by repolarization (see Figs. 13, 14B). Small-amplitude impulses arising from the plateau in some preparations (as in Fig. 13) are interpreted to be electrotonically decremented impulses arising in the portion of the axon not exposed to TTX. In the preparation shown in Figure 14B, plateau potentials, with no evidence of impulse firing in the recording from the terminal, were later observed. There was no Vaseline seal; hence TTX was present in the perfusate of both chambers.

Cadmium. Cd had no consistent effect on spontaneous patterned impulse firing, nor did it block the burst response to SG nerve stimulation, even when tested in preparations without Vaseline with Cd-saline in both chambers. In 4 terminals in which the resting potential was large (more negative than -60 $\mathrm{mV}$ ), the baseline noisy, and spontaneous bursting was occurring, the addition of $\mathrm{Cd}$ to the $\mathrm{SG}$ perfusate resulted in significant depolarization of the baseline (as much as $20 \mathrm{mV}$ ). Cd did not prevent the occurrence or alter the general pattern of bursting, nor did it alter the absolute value of the plateau.

Quinine. Quinine was added to the perfusate of both chambers simultaneously in a preparation in which bursts could be evoked by brief stimuli to the SG track (Fig. 14C). It did not alter the responses.

\section{Discussion}

Comparison of action potentials recorded intracellularly from somata, axons, and terminals of crab XOSG neurosecretory cells in normal and altered salines reveals marked differences in their form and ionic dependence. These differences are not attributable to geometrical differences, but rather indicate regional differences in the types and densities of ionic conductance channels of the membrane. Few other preparations have permitted direct recording from somata and terminals in addition to axons, for example, the barnacle photoreceptor preparation (Edgington and Stuart, 1979). However, a number of studies on neurons from vertebrate and invertebrate species document differences between axonal membrane and soma or terminal membrane 
(see further below). These observations have in common the finding that soma and terminal membranes have a higher density of Ca channels than axonal membranes. However, no direct support has been obtained for the suggestion, made in connection with studies on Aplysia (Klein and Kandel, 1978), that soma membrane properties reflect those of the terminals. The observations on the barnacle photoreceptor and those reported here provide contrary cvidence.

The initial recordings from terminal dilatations (Cooke, 1977, 1985) showed several features of their electrical activity consistent with specialization for coupling of electrical with secretory mechanisms by means of admission of external $\mathrm{Ca}^{2+}$. These include (1) sufficient voltage-dependent $\mathrm{Ca}$ conductance, in addition to $\mathrm{Na}$ conductance, to sustain regenerative action potentials of terminals in reduced $\mathrm{Na}$ - or TTX-containing salines; (2) action potentials of long duration relative to those of "ordinary" crustacean axons; (3) impulse broadening during repetitive firing in some terminals; and (4) the ability to sustain impulse firing during maintained depolarization. All of these potentially enhance the admission of $\mathrm{Ca}^{2+}$ near sites of exocytosis. An absolute requirement for the presence of external $\mathrm{Ca}^{2+}$ for secretion of all of the identified hormonal peptides (Newcomb, 1983) in response to electrical stimulation or elevation of saline $K$, as well as entry of ${ }^{45} \mathrm{Ca}^{2+}$ in association with secretion, has been established for this neurosecretory system (Cooke et al., 1977; Cooke and Haylett, 1984; Stuenkel, 1985).

The present study shows that the terminals are, indeed, specialized, relative to other regions of the neuron, with respect to the characteristics mentioned. Thus, axons have few voltagedependent $\mathrm{Ca}$ channels, as they cannot be induced to give regenerative responses or conduct impulses in reduced-Na or TTXcontaining salines. Axon impulses are shorter in duration than are terminal impulses (ca. 6 vs $10 \mathrm{msec}$ ), although they are longer than impulses recorded from nonsecretory axons of the eyestalk (Cooke, 1985). Modest spike broadening can be attributed to contamination of the axonal recordings by terminal responses.

A number of preparations have provided evidence for enrichment of terminal or presynaptic membrane relative to axonal membrane with $\mathrm{Ca}$ channels. These include the squid stellate ganglion giant synapse (Katz and Miledi, 1969a), frog neuromuscular junction (Katz and Miledi, 1969b), barnacle photoreceptor (Edgington and Stuart, 1979), lobster neuromuscular junction (Niwa and Kawai, 1982), and rat (Salzberg et al., 1983) and frog (Obaid et al., 1985) neurohypophysis. Compared to all of these, the peptidergic terminals of the crab seem to be more richly endowed with $\mathrm{Ca}$ channels since, unlike them, the crab terminals produce regenerative impulses in the presence of TTX and in Na-deficient saline without the addition of pharmacological inhibitors of competing $\mathrm{K}$ conductances.

Electrical characteristics of somata varied widely. Some penetrations in the $\mathrm{XO}$ region showed no responses, perhaps representing penetrations of processes of non-XO origin (Nagano, 1986). In other XO recordings, electrotonically decremented impulses were observed, which can be interpreted as reflections of axonal activity. In this respect, these neurons resemble many, perhaps the majority, of arthropod neurons. However, recordings were obtained in which overshooting action potentials were observed. These showed mixed $\mathrm{Na}^{+}$and $\mathrm{Ca}^{2+}$ dependence and had durations intermediate between axon and terminal impulses. In contrast to terminals, they did not exhibit impulse broadening, and declined in amplitude during repetitive firing. It is unclear whether differences in the extent of impulse invasion of the XO somata bear a relation to heterogeneity of the population (see introduction) or reflect differences in the distance of the soma from an impulse-generating region, the soma membrane itself being inexcitable in all cases. In recording from somata of the in situ crayfish XO, Glantz and colleagues (1983) noted variability of impulse invasion (Pacifastacus sp.), while Iwasaki and Satow (1971) mentioned only overshooting potentials (Procambarus clarkii). Intracellular staining with Lucifer yellow in the XO of the crab Portunus trituberculatus revealed 2 morphological cell types (Nagano, 1986), which may provide an anatomical basis for electrophysiological differences.

In addition to regional differences in the densities of $\mathrm{Na}$ and $\mathrm{Ca}$ channels, the observations indicate regional differences in $\mathrm{K}^{+}$conductances. While somata and terminal action potentials were typically followed by hyperpolarizing afterpotentials, those of the large axons sampled were depolarizing. Consistent with previous observations on crustacean axons that activation of $K$ conductance plays but a small role in repolarization of action potentials (Julian et al., 1962), TEA had little effect on the axonal action potential duration. By contrast, TEA resulted in a 50fold prolongation of the terminal action potential. Thus, terminal membrane may be presumed to include TEA-sensitive, voltage-dependent $\mathrm{K}$ channels $\left(I_{\mathrm{K}}\right.$ : Adams et al., 1980). Voltagedependent inactivation of $I_{\mathrm{K}}$ is proposed as the mechanism responsible for impulse broadening in molluscan neurons (Aldrich et al., 1979; Ruben and Thompson, 1984) and is consistent with observations in the crab terminals (Cooke, 1985). The prominence of this conductance in terminals, suggested by the effects of TEA, is consistent with a role of $I_{\mathrm{K}}$ in impulse broadening. TEA increased the duration of impulses recorded from somata much less than those of the terminals, and somata do not show impulse broadening, further supporting a role of $I_{\mathrm{K}}$ inactivation in impulse broadening.

The presence of Ca-mediated $\mathrm{K}$ conductance $\left(I_{\mathrm{C}}\right.$ : Adams et al., 1980) in terminals is suggested by the persistence of hyperpolarizing afterpotentials in TEA and by the remarkably long depolarizations recorded in Ba-containing salines. TEA does not inhibit $I_{\mathrm{C}}$ in crustacean cardiac ganglion neurons (Tazaki and Cooke, 1983), and $\mathrm{Ba}$ is incapable of activating it in molluscan neurons (Gorman and Hermann, 1979). Quinine, an inhibitor of $I_{\mathrm{C}}$ in some crustacean neurons (Hanani and Shaw, 1977), did not consistently inhibit hyperpolarizing afterpotentials. It may be that the contribution of $I_{\mathrm{C}}$ is small relative to $I_{\mathrm{K}}$ in terminals. Quinine resulted in decreased rates of impulse repolarization and reduction of hyperpolarizing afterpotentials during repetitive firing in somata, interpretable as resulting from a block of $I_{\mathrm{C}}$ present in somata.

Long plateaus were recorded from terminals in $\mathrm{Ba}$ - or TEAcontaining salines. In the presence of TEA, plateaus were observable in $\mathrm{Na}$-free or $\mathrm{Ca}$-free salines. Such plateaus may result from the presence of slowly inactivating or noninactivating, nonspecific cation channels analogous to those described from non-neural secretory cells (Yellen, 1982). Two types of nonspecific cation conductance channels have recently been observed under patch-clamp recording conditions from acutely isolated SG terminals (Lemos et al., 1986).

Our observations suggest further regional specialization of function within the individual neurosecretory neuron with a site for initiation of action potentials and, perhaps, for generation of burst-forming potentials. Functional arguments, as well as analogy with other arthropod neurons, lead to the suggestion that the site would be a region of the proximal axon near the 
point of emergence of major collaterals (Andrew et al., 1978; Glantz et al., 1983; Cooke and Stuenkel, 1985). These collaterals enter the neuropil of the underlying ganglion and are presumed to receive synaptic input. In the great majority of our recordings, impulse initiation occurred at the proximal axon region, whether spontaneous or evoked by depolarization of the terminal. Subthreshold axonal stimulation when combined with subthreshold depolarizing current in the terminal results in impulse initiation (Cooke, 1985). These observations suggest the ability of electrical events at the terminals to influence the presumed integrative region of the proximal axon.

Membrane giving rise to the depolarizing plateaus underlying impulse bursts may also be localized in the proximal axon. However, in preparations in which bursts could be evoked, stimulation across the Vascline bridge was cffective, whercas depolarization of a terminal was not. Thus, the initiation of bursting may have a higher threshold than that for impulse initiation or be at an electrotonically greater distance from the terminals.

The occurrence of evoked and spontaneous rhythmic bursting gains significance from observations on the mammalian neurohypophysis that such patterned firing is very much more effective in releasing peptide hormones than is an equivalent number or frequency of nonpatterned impulses (e.g., Dutton and Dyball, 1979; Cazalis et al., 1985). Equivalent information is not currently available for the XOSG system. Iwasaki and Satow (1969) recorded spontaneous rhythmic bursting from crayfish XO somata. They found that the interburst interval could be altered, the phase reset, or the burst terminated by current passing, suggesting the endogenous generation of the patterning. Because in our experiments the system has been isolated, and morphological studies (on Cardisoma: Weatherby, 1981; for others, see Cooke and Sullivan, 1983) fail to reveal synaptic contacts among the neurosecretory cells, we presume that the bursts are endogenously generated. The ability to evoke plateau potentials during perfusion with TTX-containing saline suggested their possible similarity to the slow, TTX-resistant, calcium-dependent regenerative potentials ("driver potentials") underlying burst formation in crustacean cardiac ganglion cells (Tazaki and Cooke, 1983). Cd rapidly and reversibly inhibits driver potentials. It is thus intriguing that plateau potentials were observable in this system in the presence of both TTX and Cd. The ionic basis of these potentials remains to be determined.

\section{References}

Adams, D. J., S. J. Smith, and S. H. Thompson (1980) Ionic currents in molluscan soma. Annu. Rev. Neuroscience 3: 141-167.

Aldrich, R. W., Jr., P. A. Getting, and S. H. Thompson (1979) Mechanism of frequency-dependent broadening of molluscan neurone soma spikes. J. Physiol. (Lond.) 291: 531-544.

Andrew, R. D., I. Orchard, and A. S. M. Saleuddin (1978) Structural re-evaluation of the neurosecretory system in the crayfish eyestalk. Cell Tissue Res. 190: 235-246.

Cazalis, M., G. Dayanithi, and J. J. Nordmann (1985) The role of patterned bursts and interburst interval on the excitation-coupling mechanism in the isolated rat neural lobe. J. Physiol. (Lond.) 369: 45-60.

Cooke, I. M. (1977) Electrical activity of neurosecretory terminals and control of peptide hormone release. In Peptides in Neurobiology, $\mathbf{H}$. Gainer, ed., pp. 345-374, Plenum, New York.

Cooke, I. M. (1981) Electrical activity in relation to hormone secretion in the X-organ-sinus gland system of the crab. In Neurosecretion: Molecules, Cells, Systems, D. S. Farner and K. Lederis, eds., pp. 235247, Plenum, New York.

Cooke, I. M. (1985) Electrophysiological characterization of peptider- gic neurosecretory terminals. J. Exp. Biol. 118: 1-35.

Cooke, I. M., and B. A. Haylett (1984) Ionic dependence of secretory and electrical activity evoked by elevated $\mathrm{K}^{+}$in a peptidergic neurosecretory system. J. Exp. Biol. 113: 289-321.

Cooke, I. M., and E. L. Stuenkel (1985) Electrophysiology of invertebrate neurosecretory cells. In The Electrophysiology of the Secretory Cell, A. M. Poisner and J. Trifaro, eds., pp. 115-164, Elsevier, Amsterdam.

Cooke, I. M., and R. E. Sullivan (1982) Hormones and neurosecretion. In The Biology of Crustacea, Vol. 3, H. Atwood and D. Sandeman, eds., pp. 205-290, Academic, New York.

Cooke, I. M., B. A. Haylett, and T. M. Weatherby (1977) Electrically elicited neurosecretory and electrical responses of the isolated crab sinus gland in normal and reduced calcium salines. J. Exp. Biol. 70: 125-149.

Dutton, A., and R. E. J. Dyball (1979) Phasic firing enhances vasopressin release from the rat neurohypophysis. J. Physiol. (Lond.) 290: 433-440.

Edgington, D. R., and A. E. Stuart (1979) Calcium channels in the high resistivity axonal membrane of photoreceptors of the giant barnacle. J. Physiol. (Lond.) 294: 433-445.

Glantz, R. M., M. D. Kirk, and H. Aréchiga (1983) Light input to crustacean neurosecretory cells. Brain Res. 265: 307-311.

Gorman, A. L. F., and A. Hermann (1979) Internal effects of divalent cations on potassium permeability in molluscan neurones. J. Physiol. (Lond.) 296: 393-410.

Hagiwara, S., and L. Byerly (1981) Calcium channel. Annu. Rev. Neurosci. 4: 69-125.

Hanani, M., and C. Shaw (1977) A potassium contribution to the response of the barnacle photoreceptor. J. Physiol. (Lond.) 270: 151163.

Iwasaki, S., and Y. Satow (1969) Spontaneous grouped discharge of secretory neuron soma in X-organ of crayfish Procambarus clarkii. J. Physiol. Soc. Jpn. 31: 629-630.

Iwasaki, S., and Y. Satow (1970) Spike initiation of neurosecretory neuron soma in Na deficient or tetrodotoxin medium. J. Physiol. Soc. Jpn. 32: 37-38.

Iwasaki, S., and Y. Satow (1971) Sodium- and calcium-dependent spike potentials in the secretory neuron soma of the crayfish. J. Gen. Physiol. 57: 216-238.

Julian, F. J., J. W. Moore, and D. E. Goldman (1962) Current-voltage relations in the lobster giant axon membrane under voltage clamp conditions. J. Gen. Physiol. 45: 1217-1238.

Katz, B., and R. Miledi (1969a) Tetrodotoxin-resistant electrical activity in presynaptic terminals. J. Physiol. (Lond.) 203: 459-487.

Katz, B., and R. Miledi (1969b) Spontaneous and evoked activity of motor nerve endings in calcium Ringer. J. Physiol. (Lond.) 203: 689706.

Keller, R. (1983) Biochemistry and specificity of the neurohemal hormones in Crustacea. In Neurohemal Organs of Arthropods, A. P. Gupta, ed., pp. 118-148, Thomas, Springfield, IL.

Klein, M., and E. R. Kandel (1978) Presynaptic modulation of voltagedependent $\mathrm{Ca}^{2+}$ current: Mechanism for behavioral sensitization in Aplysia californica. Proc. Natl. Acad. Sci. USA 75: 3512-3516.

Lemos, J. R., J. J. Nordmann, I. M. Cooke, and E. L. Stuenkel (1986) Single channels and ionic currents in peptidergic nerve terminals. Nature 319: 410-412.

Nagano, M. (1982) Intra- and extracellular recording from a crab neurosecretory system. J. Physiol. Soc. Jpn. 44: 362 .

Nagano, M. (1986) Heterogeneity of neurons in the crustacean $\mathrm{X}$-organ as revealed by intracellular recording and injection of horseradish peroxidase. Brain Res. 362: 379-383.

Nagano, M., and I. M. Cooke (1981) Electrical activity in the crab $\mathrm{X}$-organ sinus gland system. Site of initiation, ionic bases, and pharmacology. In Neurosecretion: Molecules, Cells, Systems, D. S. Farner and K. Lederis, eds., pp. 504-505, Plenum, New York.

Nagano, M., and I. M. Cooke (1983) Morphology and intracellularly recorded activity of peptide neurosecretory somata, axons, and terminals: Differences in ionic mechanisms. Int. Union Physiol. Soc. Proc. 15: 194.

Newcomb, R. W. (1983) Peptides in the sinus gland of Cardisoma carnifex: Isolation and amino acid analysis. J. Comp. Physiol. B 153: 207-221.

Niwa, A., and N. Kawai (1982) Tetrodotoxin-resistant propagating action potentials in presynaptic axon of the lobster. J. Neurophysiol. 47: 353-361. 
Obaid, A. L., R. K. Orkand, H. Gainer, and B. M. Salzberg (1985) Active calcium responses recorded optically from nerve terminals of the frog neurohypophysis. J. Gen. Physiol. 85: 481-489.

Potter, D. D. (1956) Observations on the neurosecretory system of portunid crabs. Ph.D. thesis, Harvard University, Cambridge, MA.

Rchm, M. (1959) Obscrvations on the localisation and chcmical constitution of neurosecretory material in nerve terminals in Carcinus maenas. Acta Histochem. 7: 88-106.

Ruben, P., and S. Thomson (1984) Rapid recovery from K current inactivation on membrane hyperpolarization in molluscan neurons. J. Gen. Physiol. 84: 861-875.

Rubin, R. (1982) Calcium and Cellular Secretion, Plenum, New York

Salzberg, B. M., A. L. Obaid, D. M. Sensemann, and H. Gainer (1983) Optical recording of action potentials from vertebrate nerve terminals using potentiometric probes provides evidence for sodium and calcium components. Nature 306: 36-40.

Stanfield, P. R. (1983) Tetraethylammonium ions and the potassium permeability of excitable cells. Rev. Physiol. Biochem. Pharmacol. 97: 1-67.
Stuenkel, E. L. (1983) Biosynthesis and axonal transport of proteins and identified hormones in the $\mathrm{X}$-organ sinus gland neurosecretory system. J. Comp. Physiol. 153: 191-205.

Stuenkel, E. L. (1985) Simultaneous monitoring of electrical and secretory activity in peptidergic neurosecretory terminals of the crab. J. Physiol. (Lond.) 359: 163-187.

Stuenkel, E. L. (1986) A common precursor to two major crab neurosecretory peptides. Peptides 7: 397-406.

Tazaki, K., and I. M. Cooke (1983) Neuronal mechanism underlying rhythmic bursts in crustacean cardiac ganglia. In Neural Origin of Rhythmic Movements, A. Roberts and B. Roberts, eds., Soc. Exp. Biol. Symp. 37: 129-157.

Weatherby, T. M. (1981) Ultrastructural study of the sinus gland of the crab Cardisoma carnifex. Cell Tissue Res. 220: 293-312.

Yellen, G. (1982) Single $\mathrm{Ca}^{2+}$-activated nonselective cation channels in neuroblastoma. Nature 296: 357-359. 